\title{
Cuestiones de procedimiento en los casos Costa Rica c. Nicaragua y Nicaragua c. Costa Rica ante la Corte Internacional de Justicia
}

Fecha de recepción: $1^{\circ}$ de febrero de 2016

Fecha de aceptación: 27 de junio de 2016

Doi: 10.12804/revistas.urosario.edu.co/acdi/a.5299

Juan José Quintana*

Resumen: en el presente artículo, se examinan diversas cuestiones del procedimiento que se sigue en los litigios contenciosos que se ventilan ante la Corte Internacional de Justicia, a la luz de varios pronunciamientos de la Corte contenidos en la sentencia del 16 de diciembre de 2015, en dos procesos acumulados entre Costa Rica y Nicaragua, a saber, el caso "Ciertas actividades adelantadas por Nicaragua en la región fronteriza”, elevado por Costa Rica, y el caso "Construcción de una carretera en Costa Rica a lo largo del río San Juan”, elevado por Nicaragua. En esta sentencia, la Corte incluyó importantes decisiones en relación con aspectos procesales de carácter técnico, como la acumulación de procedimientos, las demandas reconvencionales, las medidas provisionales de protección, las medidas de reparación, el manejo de la evidencia y las costas judiciales. En varios

* Embajador de Colombia en La Haya (Países Bajos). Las opiniones expresadas en este artículo son estrictamente personales y no reflejan necesariamente las opiniones del gobierno de Colombia ni del Ministerio de Relaciones Exteriores. Correo electrónico: jjquintanaa@gmail.com

Para citar este artículo: Quintana, J. J. "Cuestiones de procedimiento en los casos Costa Rica c. Nicaragua y Nicaragua c. Costa Rica ante la Corte Internacional de Justicia”, Anuario Colombiano de Derecho Internacional (ACDI), 2017, 10, pp. 117-159. Doi: 10.12804/revistas.urosario.edu.co/acdi/a.5299 
casos, esta decisión introduce considerables innovaciones respecto de la jurisprudencia previa de la CIJ sobre temas procesales.

Palabras clave: Corte Internacional de Justicia, litigio, proceso judicial, procedimiento, procedimientos incidentales, acumulación de casos, demanda reconvencional, medidas provisionales, reparación, evidencia y prueba, testigos y peritos, costas judiciales.

Questions of Procedure in the cases Costa Rica c. Nicaragua and Nicaragua c. Costa Rica before the International Court of Justice

Abstract: This paper is concerned with several questions of the procedure followed when litigation is conducted before the International Court of Justice, in the light of the judgment of the Court rendered on 16 December 2015, in two cases between the same parties that were joined, i. e. "Certain activities carried out by Nicaragua in the border area", filed by Costa Rica against Nicaragua, and "Construction of a road in Costa Rica along the San Juan river", filed by Nicaragua against Costa Rica. In this judgment important decisions by the ICJ can be found related to technical aspects of procedure such as joinder, counterclaims, provisional measures, remedies, evidence and proof of facts and costs. In several cases this decision introduces significant innovations into the Court's previous case-law regarding litigation before it.

Key words: International Court of Justice, litigation, judicial process, procedure, incidental proceedings, joinder, counterclaims, provisional measures, remedies, evidence and proof of facts, experts and witnesses, costs.

Questões de procedimento nos casos Costa Rica c. Nicarágua e Nicarágua c. Costa Rica ante a Corte Internacional de Justiça

Resumo: No presente artigo, examinam-se diversas questões do procedimento que se segue nos litígios contenciosos que se ventilam ante a Corte Internacional de Justiça, à luz de vários pronunciamentos da Corte contidos na sentença do 16 de dezembro de 2015, em dois processos 
acumulados entre a Costa Rica e a Nicarágua, a saber, o caso "Certas atividades adiantadas pela Nicarágua na região fronteiriça”, elevado pela Costa Rica, e o caso "Construção de uma estrada na Costa Rica ao longo do rio San Juan”, elevado pela Nicarágua. Nesta sentença, a Corte incluiu importantes decisões em relação com aspectos processais de carácter técnico, como a acumulação de procedimentos, as demandas reconvencionais, as medidas provisionais de proteção, as medidas de reparação, a gestão da evidência e as costas judiciais. Em vários casos, esta decisão introduz consideráveis inovações respeito da jurisprudência prévia da CIJ sobre temas processais.

Palavras-chave: Corte Internacional de Justiça, litigio, processo judicial, procedimento, procedimentos incidentais, acumulação de casos, demanda reconvencional, medidas provisionais, reparação, evidência e prova, testemunhas e peritos, costas judiciais.

\section{Presentación}

El 16 de diciembre de 2015, la Corte Internacional de Justicia (CIJ) profirió sentencia en dos litigios entre Costa Rica y Nicaragua que previamente habían sido objeto de una acumulación procesal. ${ }^{1}$ Estos dos países ya se habían enfrentado ante la CIJ en dos ocasiones ${ }^{2}$ y aún hoy mantienen otro pleito ante el mismo tribunal, relacionado con la delimitación marítima entre ambos países en ambos océanos. ${ }^{3}$

El primer caso ("Ciertas actividades adelantadas por Nicaragua en la región fronteriza", en adelante "Costa Rica c. Nicaragua") se inició por demanda de Costa Rica del 18 de noviembre de 2010 y se refería a ciertas obras emprendidas por Nicaragua en la desembocadura del río San Juan. El segundo ("Construcción de una carretera en Costa Rica a lo largo del

\footnotetext{
1 ICJ, Certain activities carried out by Nicaragua in the border area (Costa Rica c. Nicaragua); Construction of a road in Costa Rica along the San Juan river (Nicaragua c. Costa Rica), Merits, Judgment of 16 December 2015 [en adelante: Judgment]).

2 ICJ, Border and transborder armed actions (Nicaragua c. Costa Rica) (1986-1987); Dispute regarding navigational and related rights (Costa Rica c. Nicaragua) (2005-2009).

3 ICJ, Maritime delimitation in the Caribbean Sea and the Pacific Ocean (Costa Rica c. Nicaragua), caso iniciado por demanda presentada por Costa Rica el 25 de febrero de 2014. Al momento de elaboración del presente texto, este caso estaba en la etapa escrita.
} 
río San Juan", en adelante "Nicaragua c. Costa Rica") comenzó mediante demanda presentada por Nicaragua el 22 de diciembre de 2011 y versaba sobre la construcción de una carretera por Costa Rica en su margen del mismo río. La Corte tardó cinco años en resolver el primero de los dos casos y cuatro años en resolver el segundo.

En general, se considera que en ambos casos Nicaragua, a pesar de tener una reputación bien ganada de veterano litigante ante la Corte de La Haya, sufrió varios reveses de importancia, representados en decisiones sobre procedimiento y sobre el fondo inequívocamente favorables a Costa Rica.

En el caso iniciado por Costa Rica, por ejemplo, la Corte indicó las medidas provisionales pedidas por ese país, reafirmó en dos ocasiones esas medidas y declinó ocuparse de varias demandas reconvencionales presentadas por Nicaragua. En el caso iniciado por Nicaragua, la Corte negó una solicitud nicaragüense sobre indicación de medidas provisionales proprio motu y rechazó después una solicitud de medidas provisionales formulada por la propia Nicaragua. En sentido procesal, parecería que el mayor logro de Nicaragua fue que la Corte acumulara los procedimientos en ambos litigios, aunque, como se verá más adelante, esta fue una decisión que tuvo escasos efectos prácticos y que resulta difícil de justificar a la luz del régimen y práctica de la Corte. ${ }^{4}$

En cuanto al fondo de los procesos, Costa Rica salió claramente victoriosa de esta contienda judicial. En el primer caso, la Corte concluyó que Costa Rica poseía soberanía sobre el territorio en disputa entre las partes (una pequeña porción de terreno localizada en el área de la desembocadura del río San Juan en el mar Caribe) y que las obras de drenaje de un caño efectuadas allí por Nicaragua violaban dicha soberanía. ${ }^{5}$

4 Otra (relativamente pequeña) victoria procesal de Nicaragua fue que convenció a la Corte de que en el caso Nicaragua c. Costa Rica debía haber una segunda ronda de alegatos escritos (Judgment, par. 28).

5 La Corte había definido los límites del 'territorio en disputa' en su providencia sobre medidas provisionales de 2011 y confirmó esa definición en la sentencia sobre el fondo (Judgment, par. 69). En una interesante variación, el juez ad hoc de Nicaragua (Guillaume) sostuvo en una declaración añadida al fallo que la pretensión de Costa Rica relativa a la cuestión de la soberanía era inadmisible debido a que fue formulada en la memoria y no en la demanda introductiva de instancia y, por lo tanto, constituía lo que en el procedimiento ante la CIJ se denomina una 'pretensión nueva', con la cual el que era originalmente un contencioso sobre responsabilidad se vio transformado en un contencioso territorial (ibid., Declaration of judge ad hoc Guillaume, pars. 16-17. El juez Gevorkian, quien también votó en 
En consecuencia, la Corte condenó a Nicaragua por dicha violación y le ordenó pagar compensación por el daño material ocasionado a Costa Rica.

En el caso iniciado por Nicaragua, la Corte rechazó todas las solicitudes de medidas de reparación presentadas por Nicaragua y se limitó a producir una medida de reparación simbólica por el incumplimiento de Costa Rica de una obligación de carácter procesal, bajo la forma de una declaración incluida en el propio fallo. Si a esto se suma que las siete secciones que conforman el dispositif fueron adoptadas, bien por unanimidad o bien por mayorías abrumadoras, debe concluirse que la imagen de Nicaragua como invicto litigante ante la Corte Internacional de Justicia ha sufrido una mella de cierta consideración.

Desde el punto de vista del derecho sustantivo, los casos tienen especial importancia para el desarrollo del derecho ambiental internacional, por la forma en que la Corte abordó varios conceptos clave de esa normativa. Sin embargo, el presente comentario se concentra exclusivamente en aspectos del procedimiento que se sigue en litigios ante la CIJ, en los cuales hubo desarrollos de interés que fueron plasmados en las numerosas providencias emitidas a lo largo del proceso y en la sentencia de 2015. Luego de recapitular la evolución que tuvieron los dos procesos (punto 2), se considerará la forma como la Corte abordó los temas de la acumulación (3.1), las demandas reconvencionales (3.2), las medidas provisionales (3.3), las medidas de reparación (3.4), el manejo de la evidencia (3.5) y las costas judiciales (3.6).

\section{Evolución de los litigios paralelos entre Costa Rica y Nicaragua}

Los dos casos tuvieron un tortuoso desarrollo procesal, puesto que en ambos la Corte debió emitir no menos de seis decisiones interlocutorias en forma de providencias, resolviendo aspectos colaterales relativos a

contra de esta sección del dispositif, expresó una opinión similar en una declaración añadida al fallo. Sobre el concepto de 'pretensiones nuevas', ver Quintana, Juan José, Litigation at the International Court of Justice, Practice and Procedure, Brill-Nijhoff, Leiden-Boston, 2015, pp. 258-263 [en adelante: Quintana, Litigation...]; Yee, S., “Article 40”, in Zimmermann, A. et al (Eds.), The Statute of the International Court of Justice - A commentary, Oxford University Press, Oxford, 2012, pp. 975-982 [en adelante: Oxford Commentary...]. 
medidas provisionales, ${ }^{6}$ acumulación de procedimientos ${ }^{7}$ y admisibilidad de reconvenciones. ${ }^{8}$

A partir del 17 de abril de 2013, los dos casos fueron acumulados formalmente por la Corte, lo que indicaría que desde entonces el procedimiento iba a ser uniforme. Sin embargo, las acciones procesales subsiguientes siguieron un curso independiente, con el resultado de que, procesalmente, los dos casos tuvieron en realidad un manejo y una evolución separados.

En Costa Rica c. Nicaragua, por ejemplo, solo hubo una ronda de alegatos y el procedimiento escrito culminó el 19 de septiembre de 2012, cuando las partes anunciaron que no buscarían una segunda ronda de alegatos. ${ }^{9}$ En Nicaragua c. Costa Rica, el demandante solicitó una segunda ronda y, a pesar de las objeciones del demandado, la Corte decidió autorizar la presentación de una réplica y una dúplica, con lo cual el procedimiento escrito solo vino a concluir el 2 de febrero de 2015, con el depósito de esta última pieza.

En segundo lugar, aunque en ambos casos hubo solicitudes de medidas provisionales, la Corte tramitó estas por separado y, de hecho, declinó una solicitud de Nicaragua de considerar en forma conjunta la

\footnotetext{
6 ICJ, Certain activities carried out by Nicaragua in the border area (Costa Rica c. Nicaragua), Provisional measures, Order of 8 March 2011, ICJ Reports 2011, p. 6 [en adelante: Order of 8/3/2011]; ICJ, Certain activities carried out by Nicaragua in the border area (Costa Rica c. Nicaragua); Construction of a road in Costa Rica along the San Juan river (Nicaragua c. Costa Rica), Order of 16 July 2013, Provisional measures, ICJ Reports 2013, p. 230 [en adelante: Order of 16/7/2013]; ICJ, Certain activities carried out by Nicaragua in the border area (Costa Rica c. Nicaragua); Construction of a road in Costa Rica along the San Juan river (Nicaragua c. Costa Rica), Provisional measures, Order of 22 November 2013, ICJ Reports 2013, p. 354 [en adelante: Order of 22/11/2013]; ICJ, Construction of a road in Costa Rica along the San Juan river (Nicaragua c. Costa Rica); Certain activities carried out by Nicaragua in the border area (Costa Rica c. Nicaragua), Provisional measures, Order of 13 December 2013, ICJ Reports 2013, p. 398 [en adelante: Order of 13/12/2013].

7 ICJ, Certain activities carried out by Nicaragua in the border area (Costa Rica c. Nicaragua), Joinder of proceedings, Order of 17 April 2013, ICJ Reports 2013, p. 166; Construction of a road in Costa Rica along the San Juan river (Nicaragua c. Costa Rica), Joinder of proceedings, Order of 17 April 2013, ICJ Reports 2013, p. 184 [en adelante: Orders of $17 / 4 / 2013]$.

8 ICJ, Certain activities carried out by Nicaragua in the border area (Costa Rica c. Nicaragua); Construction of a road in Costa Rica along the San Juan river (Nicaragua c. Costa Rica), Counter-claims, Order of 18 April 2013, ICJ Reports 2013, p. 200 [en adelante: Order of $18 / 4 / 2013]$.

9 Judgment, par. 16.
} 
segunda demanda de medidas provisionales de Costa Rica en el primer caso y su propia demanda formulada en el segundo. ${ }^{10}$ Además, mientras la Corte aceptó las dos solicitudes consecutivas de medidas provisionales de Costa Rica, Nicaragua fracasó en ese mismo empeño.

Finalmente, en Costa Rica c. Nicaragua, el demandado presentó en su contramemoria varias demandas reconvencionales que la Corte debió evacuar antes de pasar al procedimiento oral. La Corte resolvió sobre la admisibilidad de estas demandas (rechazándolas todas en la práctica) mediante una providencia del 18 de abril de 2013 y, por lo tanto, a partir de esa fecha, este caso (pero no el otro) estuvo listo para audiencias o en état. No obstante, como para entonces ya se había decidido la acumulación de los dos procesos, Costa Rica tuvo que esperar dos años hasta que el procedimiento escrito en el caso Nicaragua c. Costa Rica - en el cual, como se vio, hubo dos rondas de alegatos- se agotó y la Corte pudo fijar las fechas para el procedimiento oral común en los dos casos acumulados.

Las audiencias celebradas en abril y mayo de 2015 también reflejaron un manejo separado de los dos pleitos: el caso Costa Rica c. Nicaragua fue debatido entre el 14 y 17 de abril y el caso Nicaragua c. Costa Rica, entre el 20 de abril y el $1^{\circ}$ de mayo. Las partes presentaron sus argumentos sobre cada controversia en diferentes momentos, utilizaron medios de prueba nítidamente separados, formularon sus peticiones finales en forma secuencial y solicitaron de la Corte decisiones bien diferenciadas sobre los asuntos en disputa en cada caso.

En cuanto a la sentencia final, constituye en realidad una amalgama de dos sentencias en las cuales se examinan por separado los hechos y el derecho aplicable en cada uno de los dos asuntos y se llega a conclusiones judiciales independientes en relación con dos conjuntos de pretensiones netamente diferenciadas. Como resultado de lo decidido por la Corte con respecto a reparación, además, si se presenta determinado supuesto fáctico, habrá lugar a un procedimiento adicional sobre este tema, pero referido única y exclusivamente al caso Costa Rica c. Nicaragua. ${ }^{11}$

\footnotetext{
10 Ibid., par. 25.

11 Judgment, par. 229 (5) (b).
} 


\section{Desarrollos jurisprudenciales en materia de procedimiento}

\subsection{Acumulación de procedimientos}

La acumulación o consolidación de procedimientos es una figura procesal bien conocida en todos los sistemas jurídicos, que busca facilitar la administración de justicia y, sobre todo, asegurar que, cuando un tribunal se ve enfrentado a varios casos simultáneos referidos a una misma materia, tanto el órgano de adjudicación como los litigantes mismos puedan ahorrar esfuerzos y recursos y litigar todas las cuestiones en juego en forma unificada, de un modo rápido y expedito.

Esta figura solo había sido utilizada hasta ahora por la CIJ en dos oportunidades, en los casos South West Africa y North Sea Continental Shelf. ${ }^{12}$ Refiriéndose a estos ejemplos de acumulación, la Corte expresó que, "cuando la Corte, o su predecesora, ha ejercido su facultad de acumular procedimientos, lo ha hecho en circunstancias en las que la acumulación sería consonante, no solamente con los principios de la adecuada administración de justicia, sino también con la necesidad de economía judicial [...]. Cualquier decisión a ese efecto será tomada a la luz de las circunstancias específicas de cada caso". ${ }^{13}$

Más interesantes son quizá varias instancias en las que, por diversas razones, la Corte no ordenó la acumulación y prefirió manejar los diferentes casos en forma paralela, por ejemplo, fijando plazos idénticos para la presentación de escritos, celebrando audiencias en las mismas fechas o en forma consecutiva y/o leyendo decisiones virtualmente idénticas en una misma fecha. Ejemplos de estos casos 'pareados' en los que no hubo acumulación formal abundan y entre ellos se pueden citar los asuntos Jurisdicción sobre pesquerías (Reino Unido y Alemania versus Islandia); Ensayos nucleares (Australia y Nueva Zelanda versus Francia); Lockerbie (Libia

\footnotetext{
12 Quintana, Litigation..., pp. 1060-1061; Kolb, Robert, The International Court of Justice, Hart Publishing, 2013, pp. 997-1002 [en adelante: Kolb, The ICJ].

13 Orders of 17/4/2013, p. 170, par. 18; p. 187, par. 12. La traducción, al igual que en todos los restantes pasajes de jurisprudencia, es del autor, basada en la versión inglesa de las decisiones. En todas las citas se han omitido las referencias internas a otras decisiones de la CIJ.
} 
versus Reino Unido y Estados Unidos); y Kosovo (Serbia versus diez países miembros de la OTAN). ${ }^{14}$

En los casos en comento, Nicaragua le pidió a la Corte acumular los dos casos y, a pesar de que Costa Rica se opuso, la Corte accedió. En dos providencias simultáneas del 17 de abril de 2013, la Corte enumeró los siguientes factores como fundamento de su decisión:

- que los dos casos involucraban a las mismas partes y se referían a la misma área geográfica;

- que ambos casos se basaban en hechos relacionados con ciertas obras en ejecución en, a lo largo de, o en estrecha proximidad a, un río común;

- que ambos casos se referían a los efectos de dichas obras sobre el medio ambiente local y sobre la libre navegación en, y el acceso a, el mencionado río, y que ambas partes se habían referido al riesgo de sedimentación del río;

- que en ambos casos las partes también hicieron referencia a los efectos ambientales nocivos de las obras sobre el frágil ecosistema fluvial (incluyendo las reservas naturales protegidas en y a lo largo del río); y, finalmente,

- que en ambos casos las partes se refirieron a violaciones de los mismos instrumentos jurídicos, a saber, un Tratado de Límites de 1858, varios laudos arbitrales y la Convención de Ramsar. ${ }^{15}$

Sobre la base de estas consideraciones, la Corte concluyó:

Una decisión en el sentido de acumular los procedimientos le permitirá a la Corte examinar en forma simultánea la totalidad de los diversos asuntos interrelacionados que están en disputa y que han sido planteados por las partes, incluyendo cualesquiera cuestiones de hecho o de derecho que sean comunes a las disputas presentadas. En opinión de la Corte, conocer de los dos casos y decidir sobre ellos en forma conjunta tendrá ventajas significativas. La Corte no anticipa ninguna demora indebida en el procesamiento de su sentencia en los dos casos. ${ }^{16}$

Quintana, Litigation..., pp. 1061-1064.

15 Orders of $17 / 4 / 2013$, p. 170 , pars. $19-22$; p. 187 , pars. $13-16$.

16 Ibid., pp. 170-171, par. 23; pp. 187-188, par. 17.
} 
Como se observa, la Corte llegó a la conclusión de que los dos casos tenían suficientes elementos en común como para justificar la acumulación formal. Aunque la Corte no especificó cuáles eran las 'ventajas significativas' que tendría conocer conjuntamente los dos casos, está claro que, a su juicio, existían asuntos 'interrelacionados' que estaban en disputa y que había efectivamente 'cuestiones de hecho y de derecho' que resultaban comunes a las dos controversias.

La verdad es que la decisión de acumular los procesos en estos dos casos resultó un poco sorpresiva, ya que el objeto-materia de cada disputa era radicalmente diferente, a pesar de los evidentes lazos comunicantes existentes entre ambas. En sentido procesal, ya se adelantó que la acumulación no tuvo efectos prácticos, puesto que los dos casos siguieron cursos separados y condujeron a lo que en realidad constituyen dos decisiones judiciales fusionadas o amalgamadas en forma un poco artificial en un texto único. ${ }^{17}$

En retrospectiva, puede pensarse que en realidad no era necesario proceder a la acumulación formal, dado que la Corte hubiera podido utilizar mecanismos similares que también están previstos en el artículo 47 del Reglamento de la Corte (como los procedimientos comunes o las acciones comunes en procedimientos separados).${ }^{18}$ La Corte podría también haber manejado los dos casos en forma paralela y prácticamente simultánea, pero conservando los procesos separados.

\subsection{Demandas reconvencionales}

Un día después de haber decidido la acumulación, la Corte resolvió sobre las cuatro demandas reconvencionales presentadas por Nicaragua en el caso Costa Rica c. Nicaragua. ${ }^{19}$ La Corte concluyó que dos de ellas eran inadmisibles debido a falta de conexidad con la demanda principal y

\footnotetext{
17 Un efecto que sí tuvo la decisión sobre acumulación se refiere a la designación de jueces ad hoc. En el caso de Nicaragua, no hubo dificultades, porque ese país había designado a la misma persona como juez ad hoc en ambos procesos (G. Guillaume). Pero Costa Rica había designado a personas diferentes. Luego de la acumulación, el juez ad hoc designado por Costa Rica en el caso Nicaragua c. Costa Rica (B. Simma) renunció y la persona designada en Costa Rica c. Nicaragua (J. Dugard) asumió como juez ad hoc en ambos casos (Judgment, pars. 6, 13, 20).

18 Quintana, Litigation..., p. 1069.

19 Order of $18 / 4 / 2013$, p. 200.
} 
encontró la forma de eludir su pronunciamiento sobre las dos restantes en esta etapa del proceso.

Mediante la primera reconvención, Nicaragua pedía a la Corte declarar la responsabilidad de Costa Rica por los efectos nocivos que la construcción de una carretera sobre la margen derecha del río San Juan tendría sobre la navegación del río. La Corte halló que, por efecto de la acumulación de procedimientos ya efectuada, esta pretensión de Nicaragua quedaba 'subsumida' bajo una de sus pretensiones principales en el caso Nicaragua c. Costa Rica y, por lo tanto, no había necesidad de resolver sobre si era o no admisible en calidad de reconvención. ${ }^{20}$

La cuarta reconvención se refería al alegado incumplimiento por parte de Costa Rica de las medidas provisionales indicadas el 8 de marzo de 2011. Luego de registrar que Costa Rica no impugnó la admisibilidad de esta reconvención, la Corte recordó su jurisprudencia en el sentido de que, cuando ella posee competencia para decidir un caso, también la posee para examinar si se ha cumplido o no con cualesquiera medidas provisionales que ella haya podido indicar en el mismo caso. ${ }^{21}$ De allí pasó a concluir que "la cuestión del cumplimiento por ambas partes de las medidas provisionales indicadas en este caso puede ser considerada por la Corte en el caso principal, con independencia del hecho de que el demandante haya o no planteado la cuestión por medio de una demanda reconvencional". ${ }^{22}$ Por lo tanto, ambas partes estaban en libertad de presentar alegatos al respecto durante el proceso sobre el fondo y resultaba innecesario que ella se pronunciara sobre esas pretensiones de Nicaragua qua reconvenciones. ${ }^{23}$

En cuanto a las reconvenciones segunda y tercera, tenían un objetomateria que claramente las distanciaba de las pretensiones de Costa Rica. Con su segunda reconvención Nicaragua buscaba que la Corte declarara que ella se había convertido en el único soberano "sobre el área ocupada anteriormente por la bahía de San Juan del Norte". ${ }^{24}$ Mediante la tercera reconvención, Nicaragua solicitaba que la Corte concluyera que ella posee un derecho de libre navegación en el Brazo Colorado del río San Juan de

\footnotetext{
20 Ibid., p. 209, par. 24.

21 ICJ, LaGrand (Germany c. United States of America), Judgment, ICJ Reports 2001, p. 484, par. 45.

22 Order of $18 / 4 / 2013$, p. 215 , par. 40.

23 Ibid.

24 Ibid., p. 209, par. 25.
} 
Nicaragua "hasta que se restablezcan las condiciones de navegabilidad existentes en la época de la celebración del Tratado de 1858 " ${ }^{25}$

Hay varios aspectos de interés en la forma como la Corte abordó la cuestión de la admisibilidad de estas dos demandas. Aunque aquí la sentencia de 2015 no contiene innovaciones, consolida la jurisprudencia aplicable a esta figura procesal, la cual, como se recordará, no tiene base directa en el Estatuto de la Corte y se fundamenta exclusivamente en el artículo 80 del Reglamento y en la doctrina que la Corte ha proferido sobre la materia. ${ }^{26}$

En primer lugar, la Corte reafirmó que, para resolver sobre la admisibilidad de una demanda reconvencional, es innecesario conducir un procedimiento oral. En todos los casos en los que se han presentado estas demandas en las últimas décadas, la Corte ha encontrado que gracias a las observaciones escritas de las partes ella estaba lo suficientemente informada sobre las respectivas posiciones y que no era necesario organizar una audiencia pública. ${ }^{27}$ En Costa Rica c. Nicaragua, la Corte reiteró que, después de haber recibido información 'plena y detallada' de las partes respecto de la admisibilidad, no consideraba necesario escucharlas nuevamente al respecto. ${ }^{28}$

En segundo lugar, la Corte siguió la misma metodología que utilizó en los casos previos: primero, examina si la demanda en cuestión

\section{Ibid.}

26 Sobre las demandas reconvencionales, ver, en general, Quintana, Litigation..., pp. 808-837; Nouvel, Y., "La recevabilite des demandes reconventionnelles devant la Cour internationale de Justice a la lumiere de deux ordonnances recentes", Annuaire Français du droit international, 1998, 44, pp. 324-336; Salerno, F., "La demande reconventionnelle dans la procedure de la Cour Internationale de Justice", Revue General du Droit International Publique, 1999, 103, pp. 371-374; Rigaux, F., «Les demandes reconventionelles devant la Cour internationale de Justice», in Ando, N., McWhinney, E. \& Wolfrum, R. (Eds.), Liber amicorum judge Shigeru Oda, 2002, vol. 2, pp. 935-945; Rosenne, S., "Counter-claims in the International Court of Justice revisited", in Rosenne, S., Essays on international law and practice, 2007, pp. 267-293; Murphy, S., "Counter-claims", in Oxford Commentary", pp. 1000-1025; Antonopoulos, C., Counterclaims before the International Court of Justice, Springer-TMC Asser Institute, The Hague, 2011.

27 Quintana, Litigation..., pp. 825-826. Esto ha sido criticado por varios jueces y por un sector de la doctrina (ver en particular la opinión disidente del juez Cançado Trindade en el caso Jurisdictional immunities, ICJ Reports 2010, p. 342, par. 30. Ver también Antonopoulos, “Counterclaims...", pp. 147-149).

28 Order of 18/4/2013, p. 203, par. 11. 
constituye o no una auténtica reconvención, tal como ella lo ha definido en su jurisprudencia. ${ }^{29}$

Segundo, la Corte indaga si se cumplen los requisitos de admisibilidad del artículo 80 del Reglamento, es decir que la demanda reconvencional entre dentro del ámbito de la competencia de la Corte y que tenga conexión directa con el objeto de la demanda de la otra parte. ${ }^{30}$ Analizando el artículo 80, la Corte precisó dos aspectos importantes: "Los requisitos de admisibilidad según el artículo 80 del Reglamento son acumulativos: cada uno de esos requisitos debe cumplirse para que una demanda reconvencional sea hallada admisible. Al examinar esos requisitos, la Corte no está obligada por la secuencia consagrada en ese artículo". 31

En este caso, la Corte invirtió la secuencia del artículo 80 y examinó primero el requisito de conexidad. Luego de constatar que no existía conexidad directa "ni en los hechos ni en el derecho" entre las reconvenciones segunda y tercera de Nicaragua y las pretensiones de Costa Rica, encontró que no era necesario considerar si las reconvenciones cumplían o no con el requisito de la competencia. ${ }^{32}$

En relación con esto, cabe recordar que, cuando una demanda reconvencional es rechazada por cuenta de que no cumple con el requisito de la conexidad, queda la posibilidad teórica de que el Estado que la plantea la presente nuevamente ante la Corte en calidad de demanda independiente, dando origen a un nuevo asunto contencioso, siempre que, por supuesto, se satisfaga el requisito separado de que exista competencia. La situación

29 Según esta definición, las demandas reconvencionales son "actos jurídicos autónomos cuyo objeto es el de someter nuevas pretensiones a la Corte que, al mismo tiempo, están relacionadas con las pretensiones principales, en la medida en que son formuladas en calidad de reconvenciones que reaccionan frente a ellas" — ICJ, Application of the Convention on the Prevention and Punishment of the Crime of Genocide (Bosnia and Herzegovina c. Yugoslavia), Counter-claims, Order of 17 December 1997, ICJ Reports 1997, p. 256, par. 27. Reafirmado en el caso en comento (Order of 18/4/2013, p. 208, par. 19)—. También es importante que, para que califique como una auténtica reconvención, una demanda de este tipo debe formularse en la contramemoria y debe figurar entre las conclusiones contenidas en ese alegato (ibid.).

30 La Corte reiteró aquí una proposición que había avanzado en el caso Jurisdictional immunities, en el sentido de que en el contexto del artículo 80 del Reglamento el término 'admisibilidad' debe entenderse en sentido amplio, abarcando tanto el requisito jurisdiccional como el requisito de la conexidad directa (ibid., p. 208, par. 20).

31 Ibid., p. 210 , par. 27.

$32 \quad$ Ibid., p. 215 , par. 38. 
es diferente si la reconvención es rechazada por falta de jurisdicción, ya que en este caso la Corte queda impedida para conocer de la pretensión de que se trate, bajo cualquier forma que adopte. ${ }^{33}$

Un último aspecto por rescatar es que la Corte fue clara en que el requisito de la conexidad debe examinarse en sus aspectos fáctico y legal, y tomando en consideración las circunstancias específicas de cada caso. $\mathrm{Al}$ hacer esto último, enumeró ciertos factores que pueden resultar pertinentes para establecer tal conexidad y que ya había identificado en casos anteriores, aunque sin sistematizarlos:

En decisiones previas relacionadas con la admisibilidad de demandas reconvencionales, la Corte ha tomado en consideración un elenco de factores que pudieran establecer, para los fines del artículo 80, una conexión directa tanto en los hechos como en el derecho entre una demanda reconvencional y las pretensiones en el caso principal. La Corte ha considerado, de esta forma, si los hechos en los que se basa cada parte se refieren a la misma área geográfica o al mismo período [...]. La Corte también ha considerado si los hechos invocados por cada parte eran de la misma naturaleza, en cuanto a que en ellos se aleguen tipos análogos de conducta [...]. La Corte también ha examinado si existe una conexión directa entre la demanda reconvencional y las pretensiones principales de la otra parte con base en los principios o instrumentos jurídicos invocados, o cuando se considera que el demandante y el demandado perseguían el mismo objetivo jurídico mediante sus respectivas pretensiones $[\ldots]{ }^{34}$

\subsection{Medidas provisionales}

Como en el curso de los dos procesos hubo varias incidencias procesales relativas a las medidas de protección del artículo 41 del Estatuto, hubo ocasión de refinar y precisar las reglas aplicables a ciertos aspectos de esta figura: la indicación de medidas provisionales de oficio (punto 3.2.1), la modificación de medidas ya indicadas (3.2.2), la supervisión de su cumplimiento (3.2.3) y las modalidades de reparación por incumplimiento (3.2.4).

33 Quintana, Litigation..., p. 829. Esto es así debido a que en la segunda hipótesis habrá una decisión inhibitoria sobre competencia que tiene fuerza de cosa juzgada.

34 Order of $18 / 4 / 2013$, pp. 211-212, par. 32. 


\subsubsection{Indicación de medidas provisionales de oficio}

El Reglamento autoriza en su artículo 75, párrafo 1, a la Corte para "en todo momento decidir examinar de oficio si las circunstancias del asunto exigen la indicación de medidas provisionales que deban adoptar o cumplir las partes o una de ellas". Si bien es una norma que ha figurado en el Reglamento desde la época de la Corte Permanente de Justicia Internacional, la Corte en realidad nunca ha hecho uso de esta facultad..$^{35}$

En el caso Nicaragua c. Costa Rica, la Corte se vio abocada a examinar la posible aplicación de esta norma a petición de parte, lo cual parecería contradecir la noción misma de una actuación de oficio. Al depositar su memoria en diciembre de 2012, Nicaragua le solicitó a la Corte que decidiera "motu proprio si las circunstancias del caso exigían la indicación de medidas provisionales". ${ }^{36}$ La Corte solicitó a Costa Rica informarla sobre su opinión al respecto y poco después comunicó a las partes que las circunstancias del caso, tal como se presentaban en ese momento, no eran tales que justificaran el ejercicio de su facultad de indicar de oficio medidas provisionales.

No se conoce la razón que llevó a Nicaragua a formular una solicitud tan poco ortodoxa, en lugar de presentar ella misma en ese momento una solicitud de medidas provisionales. Esto lo vino a hacer Nicaragua pero mucho más adelante, en octubre de 2013, luego de que este caso hubiera sido acumulado con el caso Costa Rica c. Nicaragua y poco antes de que Costa Rica depositara su contramemoria. Como se mencionó, esta solicitud fue rechazada por la Corte un año después, en diciembre de 2013, cuando ya estaban en vigencia no una, sino dos providencias consecutivas sobre indicación de medidas provisionales adoptadas en el primer caso. En cuanto a la Corte, como optó por no razonar esta parte de su decisión, tampoco hay claridad sobre las razones que la llevaron a declinar el uso de la potestad

35 Rosenne, Shabtai, Provisional measures in international law, Oxford University Press, Oxford, 2005, pp. 174-177 [en adelante: Rosenne, Provisional measures...]; Oxford Commentary, pp. 1052-1053. En el asunto LaGrand (Alemania c. Estados Unidos), la Corte invocó formalmente el artículo 75(1) del Reglamento en su providencia de indicación de medidas provisionales, pero en ese caso tenía ante sí una solicitud autónoma de medidas formulada por la parte demandante, lo cual hace cuestionable ese caso en tanto que ejemplo de aplicación de la regla mencionada (Quintana, Litigation..., pp. 677-678).

36 Judgment, par. 17. 
que tiene para indicar medidas provisionales de oficio. Sobre este aspecto del caso, por lo tanto, las decisiones en comento arrojan escasas luces.

\subsubsection{Modificación de medidas provisionales ya indicadas}

Como ya se dijo, en Costa Rica c. Nicaragua, la Corte, actuando a petición del demandante, indicó en marzo de 2011 ciertas medidas provisionales de protección. ${ }^{37}$ Dos años después, el 23 de mayo de 2013, Costa Rica retornó a la Corte solicitando una modificación de esa providencia. En sus observaciones escritas, Nicaragua solicitó a la Corte rechazar la petición de Costa Rica y, a su vez, le pidió modificar o 'adaptar', aunque en su sentido contrario, la providencia de 2011.

Para ese fin, ambas partes invocaron el artículo 76 del Reglamento, el cual faculta a la Corte para "revocar o modificar" en cualquier momento, antes del fallo definitivo en un caso, cualquier decisión relativa a medidas provisionales que haya tomado, en razón de que se presente "un cambio en la situación" que justifique dicha acción. ${ }^{38}$

Luego de recibir observaciones escritas de las partes, la Corte rechazó ambas solicitudes pero añadió a su providencia una cláusula reafirmando las medidas indicadas previamente, en particular la exigencia genérica de que las partes debían "abstenerse de cualquier acción que pueda agravar o extender la controversia ante la Corte o hacer más difícil la solución de la misma". 39

La Corte identificó con precisión las condiciones de aplicación del artículo 76 del Reglamento, el cual no había sido invocado previamente. ${ }^{40}$ Según la Corte:

\footnotetext{
37 Order of 8 March 2011, p. 6.

38 Sobre el régimen aplicable a la modificación de medidas provisionales, ver Quintana, Litigation..., pp. 680-682; Rosenne, Provisional Measures, pp. 170-174; Oxford Commentary, p. 1060. Ver también Sarmiento Lamus, Andrés, "Revocation and modification of provisional measures orders in the International Court of Justice: the Court's order regarding certain activities carried out by Nicaragua in the border area and the case concerning construction of a road in Costa Rica along the San Juan river joint proceedings", The Law and Practice of International Courts and Tribunals, 2013, 12 (3), pp. 463-474.

39 Order of $16 / 07 / 2013$, p. 241, par. 40 (2).

40 Este artículo fue incorporado en el Reglamento en la reforma de 1978, con el fin de codificar la práctica seguida en los casos Fisheries jurisdiction (United Kingdom c. Iceland) y (Germany c. Iceland). En versiones previas del Reglamento, el tema de la modificación de las
} 
Con miras a decidir sobre las respectivas solicitudes de Costa Rica y de Nicaragua para la modificación de la providencia del 8 de marzo de 2011, la Corte debe determinar si las condiciones contempladas en el artículo 76, párrafo 1, del Reglamento de la Corte se han cumplido. [...] Por lo tanto, la Corte debe determinar primero si, tomando en consideración los hechos presentados ante ella por cada una de las partes, hay razones para concluir que la situación que justificó la indicación de medidas provisionales en marzo de 2011 ha cambiado desde esa fecha. Si eso es así, la Corte tiene luego que considerar si dicho cambio justifica una modificación por la Corte de las medidas indicadas previamente, ya sea como lo piden las partes o de alguna otra manera. ${ }^{41}$

Significa esto que la modificación de medidas provisionales requiere que se cumplan dos requisitos acumulativos: i) Que la situación existente haya cambiado (determinación a efectuarse sobre la base de la información fáctica que suministren las partes); y ii) que, en caso afirmativo, dicho cambio justifique efectivamente una modificación de las medidas ya indicadas. ${ }^{42}$ En otras palabras, en tanto puede haber un cambio en la situación que no haga necesaria una modificación de las medidas provisionales, dicha modificación no puede darse a menos que tal situación haya cambiado en forma sustancial.

Adicionalmente, la Corte precisó que, para que se cumpla el segundo requisito, es necesario que se presenten en todo caso las 'condiciones generales' que ordinariamente se exigen para la indicación de medidas provisionales:

La Corte debe ahora examinar si el cambio en la situación en el que se basa Costa Rica es tal que justifica la modificación de dicha providencia. Esto sucedería únicamente si la nueva situación, a su vez, fuera tal que requeriría la indicación de medidas provisionales, es decir, si las condiciones generales estipuladas en el artículo 41 del Estatuto de la

medidas provisionales era regulado en forma considerablemente más sucinta (Quintana, Litigation..., p. 681, n. 157; Rosenne, Provisional measures, p. 74).

41 Order of 16/7/2013, p. 234.

42 Estos criterios fueron reiterados por la Corte en una decisión ulterior -Questions relating to the seizure of certain documents and data (Timor Leste c. Australia), Request for the modification of the order indicating provisional measures of 3 March 2014, Order of 22 April 2015, par. 12-. 
Corte fueran a cumplirse también en esa instancia. A este respecto, la Corte recuerda que ella solo puede indicar medidas provisionales si se pude ocasionar un perjuicio irreparable a los derechos que constituyen el objeto de la disputa sometida al procedimiento judicial [...]. Sin embargo, esta facultad será ejercida únicamente si hay una situación de urgencia, en el sentido de que existe un riesgo real e inminente de que se puede causar perjuicio irreparable sobre los derechos en disputa antes de que la Corte pueda haber proferido su decisión final [...]. ${ }^{43}$

Es interesante recordar que en el artículo 41 del Estatuto no se estipulan en realidad las 'condiciones generales' exigidas para la indicación de medidas provisionales, enumeración que ha sido efectuada por la propia Corte en su jurisprudencia. ${ }^{44}$ En el pasaje citado, la Corte — por razones de economía procesal, probablemente- eligió referirse únicamente a dos de tales condiciones (el riesgo de un perjuicio irreparable y la condición de urgencia), pero omitió mencionar las restantes, que incluyen, según la sistematización más reciente, hecha por la propia Corte, el carácter 'plausible' de los derechos invocados y el vínculo entre tales derechos y las medidas solicitadas. ${ }^{45}$

\subsubsection{Supervisión del cumplimiento de las medidas}

En la reforma de 1978 al Reglamento, se incorporó una disposición que le permite a la Corte "solicitar información de las partes sobre cualquier cuestión relativa a la puesta en práctica de las medidas provisionales que haya indicado". ${ }^{46}$ En realidad, la Corte no suele invocar esta disposición, pero ha desarrollado una práctica paralela según la cual en ciertos casos

43 Order of 16 July 2013, p. 238, par. 30.

44 Quintana, Litigation..., p. 650; Oxford Commentary, pp. 1038-1050; Kolb, The ICJ, pp. 621-633; Brown, Chester, A Common Law of International Adjudication, Oxford, 2009, pp. 139-146.

45 Ibid., p. 651. Los requisitos de la 'plausibilidad' de los derechos invocados y su vinculación con las medidas solicitadas fueron introducidos en la jurisprudencia de la Corte en años muy recientes. Para un análisis sobre si constituyen efectivamente nuevas condiciones para la indicación de medidas provisionales, ver Quintana, Litigation..., pp. 663-666, Box \# 11-8 y "Procedural developments at the International Court of Justice", The Law and Practice of International Courts and Tribunals, 2011, 10, pp. 516-529.

46 Rosenne, Provisional measures..., pp. 178-179. 
incluye en la providencia sobre medidas provisionales una 'cláusula de supervisión', ordenándoles a las partes que le suministren información sobre las acciones adelantadas en implementación de esta. ${ }^{47}$

En Costa Rica c. Nicaragua, la evolución del caso muestra con claridad que la Corte fue asignándole una importancia cada vez mayor al cumplimiento debido de sus providencias en esta materia, a las acciones que las partes deben emprender en esa dirección mientras el caso está sub judice y, sobre todo, al papel que le corresponde jugar a la Corte misma como ente de supervisión de cumplimiento de sus decisiones sobre medidas provisionales.

En primer lugar, una cláusula estándar de supervisión figuró en el dispositif de la providencia del 8 de marzo de 2011, en los siguientes términos: "Cada parte le informará a la Corte sobre el cumplimiento por ella de las medidas provisionales enunciadas atrás". 48

Como se vio atrás, el subsecuente incumplimiento por Nicaragua de esta providencia hizo necesario que Costa Rica buscara una segunda decisión sobre indicación de medidas provisionales. En providencia del 22 de noviembre de 2013, la Corte incorporó nuevamente una cláusula de supervisión, pero esta vez con un plazo perentorio: "[La Corte] decide que las partes la informarán en forma regular, a intervalos de tres meses, sobre el cumplimiento de las medidas provisionales anunciadas atrás". ${ }^{49}$

Como se observa, esta indicación iba dirigida en forma general a ambas partes en el caso. Adicionalmente, en el caso de una de las medidas dirigidas exclusivamente a Nicaragua, la Corte incluyó unos plazos muy precisos, algo de lo cual no hay antecedentes conocidos en la práctica de la CIJ. Se trata del párrafo 53 de la providencia, el cual dispone:

La Corte es de la opinión de que el relleno de la trinchera próxima al $\operatorname{caño}^{50}$ oriental debe efectuarse en forma inmediata. En vista de las circunstancias del caso y en particular del hecho de que la excavación de la trinchera fue ejecutada por personal de Nicaragua, le corresponde

\footnotetext{
47 Quintana, Litigation..., pp. 717-718.

48 Order of 8/3/2011, p. 28, par. 86 (4) —adoptado por unanimidad-. En la sentencia sobre el fondo, se registra que las partes dirigieron a la Corte varias comunicaciones a este respecto (Judgment, par. 7).

49 Order of 22 November 2013, p. 370 , par. 59 (3). Ver también Judgment, par. 26.

50 En español en el original.
} 
ahora a Nicaragua rellenarlo [...]. Nicaragua hará esto dentro de las dos semanas siguientes a la expedición de la presente providencia e informará inmediatamente a la Corte sobre la ejecución del relleno de la trinchera y le presentará, una semana después de dicha ejecución, un informe conteniendo [sic] todos los detalles necesarios, incluyendo pruebas fotográficas. ${ }^{51}$

En segundo lugar, la Corte determinó que las medidas incluidas en la providencia de 2013 eran complementarias a las que figuraban en la providencia inicial de $2011 .{ }^{52} \mathrm{Al}$ redactar estas medidas complementarias, la Corte efectuó de facto una interpretación de la providencia inicial. Un buen ejemplo es la medida provisional relativa a la presencia de personal de cualquiera de las partes en el territorio en disputa, que en la providencia inicial iba dirigida a ambas partes. En la segunda providencia, la Corte dio las siguientes indicaciones sobre la forma como esta medida debía interpretarse y aplicarse de ahí en adelante por parte de Nicaragua:

Con respecto a la presencia de personal, infraestructura y equipo nicaragüenses en el territorio en disputa, la Corte recuerda que en su providencia del 8 de marzo de 2011 ella había indicado una primera medida provisional según la cual "[c]ada parte se abstendrá de enviar a, o mantener en, el territorio en disputa [...] cualquier personal, ya sea civil, de policía o de seguridad" [...]. La Corte considera ahora que, en vista de sus conclusiones previas con relación a la presencia en el territorio en disputa de personal ejecutando operaciones de dragado y del campamento militar nicaragüense, la medida provisional indicada en la providencia del 8 de marzo de 2011 debe ser reforzada y complementada. Por lo tanto, la Corte considera que Nicaragua, después de haber rellenado la trinchera en la playa, debe (i) asegurarse de la remoción del territorio en disputa de cualquier personal, ya sea civil, de policía o de seguridad; y (ii) impedir que dicho personal ingrese al territorio en disputa. ${ }^{53}$

\footnotetext{
51 Ibid., p. 367, par. 53. Ver también el dispositif, ibid., p. 369, par. 59 (2) (B) —adoptado por unanimidad-.

52 Ibid., p. 367, par. 51.

53 Ibid., p. 368, par. 55. Ver también el dispositif, ibid., p. 369, par. 59 (2) (C) —adoptado por unanimidad-.
} 
Otro ejemplo, igualmente claro, se refiere a la presencia en el territorio en disputa de personas particulares bajo la jurisdicción o control de Nicaragua. En la providencia del 16 de julio de 2013, relativa a las solicitudes sobre modificación de las medidas originales, la Corte se limitó a incluir en la parte motiva una frase genérica según la cual: "[...] la presencia de grupos organizados de nacionales de Nicaragua en el área en disputa acarrea el riesgo de incidentes que pueden agravar la presente controversia. Esa situación es exacerbada debido al tamaño limitado de la zona y al número de nacionales de Nicaragua que están presentes allí en forma regular. La Corte desea expresar su preocupación a este respecto". ${ }^{54}$

Al volver a examinar la situación en el contexto de la segunda solicitud de medidas y constatar que la situación se mantenía sin cambios, la Corte dio un paso más allá y pasó a ordenarle directamente a Nicaragua poner término a dicha presencia:

Con respecto a la presencia en el territorio en disputa de personas particulares bajo la jurisdicción o control de Nicaragua, la Corte ya expresó su preocupación en la providencia del 16 de julio de 2013 [...]. En vista del acceso continuado de miembros del Movimiento Ambientalista Guardabarranco al territorio en disputa (ver párrafo 47 atrás), la Corte considera que Nicaragua debe asegurarse de remover del territorio en disputa y prevenir la entrada al mismo de cualesquiera personas particulares bajo su jurisdicción o control..$^{55}$

Finalmente, al cierre de su segunda providencia, la Corte recordó a las partes que sus medidas provisionales son de obligatorio cumplimiento y añadió algo que estuvo ausente de la primera providencia: la admonición de que "la cuestión del cumplimiento de las medidas provisionales indicadas en un caso puede ser considerada por la Corte durante el procedimiento principal", citando como autoridad para esta proposición genérica su decisión previa en el mismo caso en relación con la admisibilidad de las demandas reconvencionales en el caso Costa Rica c. Nicaragua. ${ }^{56}$ Como es obvio, esto se relaciona más con el incumplimiento de las medidas

Order of 16 July 2013, p. 240, par. 37.

55 Order of 22 November 2013, p. 368, par. 56. Ver también el dispositif, ibid., p. 369, par.

59 (2) (D) —adoptado por unanimidad-.

$56 \quad$ Ibid., pp. 368-369, par. 57. 
provisionales y las alternativas de acción para el Estado afectado, tema que se tratará en el apartado siguiente.

\subsubsection{Modalidades de reparación por incumplimiento de las medidas provisionales}

Es bien conocido que desde la época de la CPJI estuvo en discusión cuál era el efecto jurídico de las medidas provisionales indicadas por la Corte Internacional en ejercicio de la facultad prevista en el artículo 41 del Estatuto. ${ }^{57} \mathrm{La}$ incertidumbre que rodeó este aspecto del régimen de la CIJ vino a ser despejada en 2001, con la sentencia sobre el fondo en el caso LaGrand (Alemania c. Estados Unidos), en la cual la Corte concluyó que las medidas provisionales que ella indica son de obligatorio cumplimiento por las partes en el caso. ${ }^{58}$

Quizá la consecuencia más importante de este pronunciamiento se refiere a las consecuencias jurídicas que tiene el incumplimiento de dichas medidas. Si las medidas provisionales que indica la Corte son de obligatorio

57 Quintana, Litigation..., pp. 703-716; Kolb, The ICJ, pp. 638-650; Brown, Chester, A Common Law of International Adjudication, Oxford, 2009, pp. 146-150.

58 Reiterado en forma explícita en varias ocasiones: ICJ, Land and maritime boundary between Cameroon and Nigeria, Merits, Judgment, ICJ Reports 2002, p. 453, par. 321; ICJ, Armed activities on the territory of the Congo (Democratic Republic of the Congo c. Uganda), Judgment, ICJ Reports 2005 , p. 258 , par. 263 ; Order of $8 / 3 / 2011$, pp. 26-27, par. 84. Entre la abundante doctrina generada al respecto, ver Yang, X., "Thou Shalt Not Violate Provisional Measures", Cambridge Law Journal, 2001, 60, pp. 441-446; Matringe, J., "L'arret de la Cour internationale de Justice dans l'affaire LaGrand (Allemagne c. Etats-Unis d'Amérique) du 27 juin 2001", Annuaire Francais du Droit International, 2001, 48, pp. 215-256; Jennings, Sir Robert, "The LaGrand Case", The Law and Practice of International Courts and Tribunals, 2002, 1, pp. 13-54; Aceves, W. J., "LaGrand (Germany c. United States), Judgment", American Journal of International Law, 2002, 96, pp. 210-218; Mennecke M. \& C. Tams, "The LaGrand case (Germany c. United States of America)", ICLQ, 2002, 51, pp. 449-455; Orakhelashvili, A., "Questions of International Judicial Jurisdiction in the LaGrand Case", Leiden Journal of International Law, 2002, 15, pp. 105-130; Frowein, J. A., "Provisional Measures by the International Court of Justice: The LaGrand Case", Zeitschrift für ausländisches öffentliches Recht und Völkerrecht, 2002, 62, pp. 55-60; Tzanakapoulos, A., "Provisional Measures Indicated by International Courts: Emergence of a General Principle of International Law", Revue Hellenique de Droit International, 2004, 57, pp. 53-84; Bekker, P. H., "Provisional Measures in the Recent Practice of the International Court of Justice", International Law Forum du droit international, 2005, 7, pp. 24-32; Kolb, R., "Note on New International Case-law Concerning the Binding Character of Provisional Measures", Nordic Journal of International Law, 2005, 74, pp. 117-130. 
cumplimiento, la consecuencia lógica es que el Estado que se abstiene de ejecutarlas viola el Estatuto, que es un tratado internacional, y, por lo tanto, incurre en responsabilidad internacional, con lo cual el otro Estado parte queda automáticamente legitimado para plantear una pretensión en ese sentido ante la Corte, adicional a las pretensiones sustantivas que formaron el objeto de su demanda inicial y, eventualmente, para solicitar algún tipo de reparación. ${ }^{59}$

Esto es justamente lo que hizo Alemania en LaGrand con notorio éxito, ya que en el dispositif de su sentencia sobre el fondo la Corte registró que los Estados Unidos habían violado una obligación que tenían en virtud de la providencia indicando medidas provisionales emitidas por la Corte y, además, dejó entrever que Alemania hubiera podido solicitar reparación bajo la forma de una indemnización. ${ }^{60}$

Esto ha inducido a otros Estados a hacer lo propio, con lo cual se ha generalizado la práctica de que, en sus peticiones finales ante la Corte, el Estado que se ha beneficiado con una medida provisional indicada por ella solicita formalmente una reparación por el daño causado por el incumplimiento de esta por la contraparte, normalmente adoptando la forma de una declaración judicial, pero sin descartar otras modalidades de reparación. ${ }^{61}$

59 Ver, a este respecto, Mendelson, Maurice, "State responsibility for breach of interim protection orders of the International Court of Justice", en Fitzmaurice, M. \& Sarooshi, D. (Eds.), Issues of State responsibility before international judicial institutions, London, 2004, pp. 35-53.

60 ICJ, LaGrand, Judgment, ICJ Reports 2001, p. 516, par. 128 (5). Alemania se limitó a pedir una declaratoria de incumplimiento de la providencia y no solicitó ninguna reparación adicional por esa violación (ibid., p. 508, par. 116).

${ }^{61}$ Ver al respecto los siguientes casos: ICJ, Land and maritime boundary between Cameroon and Nigeria (Cameroon c. Nigeria: Equatorial Guinea intervening), Judgment, ICJ Reports 2002, p. 453, pars. 321-322; ICJ, Armed activities on the territory of the Congo (Democratic Republic of the Congo c. Uganda), Judgment, ICJ Reports 2005, p. 282, par. 345 (7); ICJ, Application of the Convention on the Prevention and Punishment of the Crime of Genocide (Bosnia and Herzegovina c. Serbia and Montenegro), Judgment of 26 February 2007, paras. 458, 467-469; ICJ, Avena and other Mexican nationals (Mexico c. United States of America), Judgment, ICJ Reports 2004, p. 70, par. 152; ICJ, Request for interpretation of the judgment of 31 March 2004 in the case concerning Avena and other Mexican nationals (Mexico c. United States of America) (Mexico c. United States of America), Judgment of 19 January 2009, pars. 50-53 y par. 61 (2) (dispositif); ibid., 58-60 y par. 61 (4) (dispositif). 
En Costa Rica c. Nicaragua, el demandante le pidió a la Corte declarar que Nicaragua había incumplido las obligaciones surgidas de las dos providencias sobre medidas provisionales de marzo de 2011 y noviembre de 2013. Nicaragua, si bien reconoció que ciertas acciones de su gobierno representaban un incumplimiento de sus obligaciones a la luz de la providencia de 2011, sostuvo que declarar esto en la sentencia sobre el fondo sería redundante y que, puesto que el incumplimiento había cesado para entonces, carecía de objeto que la Corte se pronunciara. Luego de recapitular los hechos y las pretensiones de las partes, la Corte rechazó el alegato nicaraguense empleando un lenguaje inusualmente directo:

La Corte ya hizo una determinación de estos hechos en su providencia del 22 de noviembre de 2013 [...]. Sin embargo, eso fue hecho únicamente con el fin de asegurar la protección de los derechos de las partes durante el proceso judicial. La sentencia sobre el fondo es el lugar apropiado para que la Corte evalúe la situación con respecto al cumplimiento de las medidas provisionales. Por lo tanto, al contrario de lo que argumentó Nicaragua, la inclusión en la presente sentencia de una declaración de la existencia de una violación no puede ser percibida como 'redundante' y tampoco se puede afirmar que la responsabilidad por dicha violación ha cesado: lo que puede haber cesado es la violación, pero no la responsabilidad surgida de dicha violación. ${ }^{62}$

El juez Robinson fue más allá y en una opinión separada añadida a la sentencia llamó la atención sobre la gravedad de la violación nicaragüense de los derechos de Costa Rica, la cual, en su opinión, justificaba aceptar la petición de este país en el sentido de que dicha acción constituía, además de una violación de su integridad territorial, un uso ilegal de la fuerza, tesis que la Corte desestimó invocando el precedente del caso Camerún c. Nigeria. ${ }^{63}$ Este juez dijo lo siguiente:

[...] el segundo campamento militar de Nicaragua estaba en el territorio en disputa, en violación de la providencia de la Corte sobre medidas provisionales del 8 de marzo de 2011. Esto constituye un acto de desafío que muestra el propósito del Estado y debe contrastarse con la

\footnotetext{
62 Judgment, par. 126.

63 Judgment, par. 97.
} 
situación en el caso Frontera terrestre y marítima (Camerún c. Nigeria), en la cual se basa la Corte, pero en el que la presencia militar de Nigeria en el momento del proceso judicial no iba en contravención de una decisión de la Corte. Esta descarada violación de la providencia de la Corte es quizás la mejor indicación sobre el objetivo ilegal detrás de las acciones de Nicaragua, ya que revela que Nicaragua estaba preparada para ir tan lejos como para violar una providencia del órgano judicial principal de las Naciones Unidas con miras a mantener su pretensión sobre el territorio en disputa. ${ }^{64}$

En la sección del fallo en la que se ocupó de las medidas de reparación, la Corte regresó al tema del incumplimiento de las medidas provisionales, en el contexto del daño inmaterial sufrido por Costa Rica. A este respecto, la Corte encontró que la declaración de incumplimiento de las obligaciones derivadas de la providencia del 8 de marzo de 2011, incluida en la sentencia, constituía una satisfacción adecuada para Costa Rica. Como se observa, esta fórmula es lo suficientemente amplia para cubrir aquellas violaciones de la providencia de mayo de 2011 que hayan podido generar un daño material para Costa Rica, según se determine más adelante, ya sea por acuerdo de las partes o por la propia Corte, al término de un procedimiento derivado dedicado a la cuestión de la compensación. ${ }^{65}$

Con respecto al daño inmaterial, la Corte encontró que la declaración de incumplimiento de las obligaciones bajo la providencia del 8 de marzo de 2011, incluida en la sentencia, constituía una satisfacción adecuada para Costa Rica. ${ }^{66}$ Por otra parte, como la solicitud por Costa Rica de garantías de no repetición se refería también al incumplimiento de la providencia de 2011, al negar esa medida de reparación, la Corte tomó nota de que, aunque Nicaragua había efectivamente incumplido sus obligaciones a la luz de la providencia de 2011, más adelante cumplió con las

64 Ibid., Separate opinion of judge Robinson, par. 62, in fine. Este juez dedicó una entera sección de su opinión a la interpretación del párrafo 97 de la sentencia y otra a la determinación de la violación de la norma de la Carta de la ONU sobre la prohibición del uso de la fuerza.

65 Judgment, par. 142.

66 Judgment, par. 139. La declaración de incumplimiento de las medidas provisionales figura en forma prominente en el dispositif, ibid., par. 229 (3) —adoptado por unanimidad-. 
exigencias que se le formularon en la segunda providencia, proferida en noviembre de $2013 .{ }^{67}$

En síntesis, la única medida de reparación que ordenó la Corte por el incumplimiento de las medidas provisionales indicadas por la Corte en este caso fue la de satisfacción, en forma de una declaración judicial. La medida de garantías o seguridades de no repetición fue, una vez más, negada.

\subsection{Medidas de reparación}

En el tema de las medidas de reparación que otorga la Corte cuando concluye que una parte en un caso ha incurrido en la violación de una obligación internacional, la jurisprudencia reciente de la CIJ es particularmente rica. Puede decirse que poco a poco la Corte ha ido superando una timidez que la caracterizó por largo tiempo y ha ido avanzando hacia el ejercicio de una potestad cada vez más robusta en materia de medidas de reparación y, si bien hay todavía aspectos en los que ha preferido no adentrarse — como el de las garantías de no repetición-, puede observarse que se ha mostrado sensible al reparo de que en varios casos emblemáticos ante ella — vienen a la mente, por ejemplo, los casos Convención contra el genocidio (Bosnia c. Serbia) o Papeleras sobre el río Uruguay (Argentina c. Uruguay) — las medidas de reparación que ordenó al cabo de extenuantes y costosos litigios no se corresponden con las expectativas legítimas de los Estados litigantes. ${ }^{68}$

En los casos bajo estudio, las partes solicitaron a la Corte una amplia gama de medidas de reparación. Siguiendo la práctica usual en casos sometidos mediante demanda, en los dos casos fue el demandante quien pidió medidas específicas de reparación, como complemento de las declaraciones que solicitaba en el sentido de que el demandado había violado determinadas obligaciones internacionales. El demandado en cada caso se

\section{Judgment, par. 141.}

68 Tams, C. J., "Consular assistance: rights, remedies and responsibility: comments on the ICJ judgment in the LaGrand case", European Journal of International Law, 2002, 13, pp. 1257-1259; Wittich, S., "Non-material damage and monetary reparation in international law", Finnish Yearbook of International Law, 2004, 15, pp. 321-368; Gattini, A., "Breach of the obligation to prevent and reparation thereof in the ICJ's genocide judgment", European Journal of International Law, 2007, 18-4, pp. 695-713; Higgins, R., "Remedies in the International Court of Justice", en Higgins, R., Themes and theories - Selected essays, speeches, and writings in international law, Oxford University Press, Oxford, 2009, pp. 1352-1358. Sobre el manejo del tema de las medidas de reparación por otros tribunales internacionales, ver Brown, Chester, A Common Law of International Adjudication, Oxford, 2009, pp. 185-225. 
limitó a solicitar declaraciones judiciales en sentido contrario y un rechazo genérico de las restantes pretensiones del demandante.

Es así como en el primer caso Costa Rica solicitó una orden de obligatorio cumplimiento, cesación, compensación por daño material, satisfacción, garantías de no repetición y condena en costas. ${ }^{69}$ En el segundo caso, Nicaragua solicitó las medidas de restitución, cesación, compensación por daños y una orden obligatoria. ${ }^{70}$

En relación con este tema, la Corte falló claramente en favor de Costa Rica. En Costa Rica c. Nicaragua, después de concluir que Nicaragua había violado la soberanía territorial de Costa Rica, había incumplido la providencia sobre medidas provisionales del 8 de marzo de 2011 y había infringido los derechos de navegación de Costa Rica en el río San Juan, la Corte encontró que Nicaragua está obligada a pagarle compensación por daños materiales ocasionados por dichas conductas ilícitas. ${ }^{71}$ En marcado contraste, en Nicaragua c. Costa Rica, la Corte concluyó que Costa Rica había incumplido sus obligaciones bajo el derecho internacional general al no haber ejecutado un estudio de impacto ambiental en relación con la construcción de una carretera a lo largo del río San Juan, pero encontró que la declaración judicial sobre este incumplimiento constituía una medida suficiente de satisfacción para Nicaragua, rechazando explícitamente todas las restantes solicitudes sobre formas de reparación hechas por ese país. ${ }^{72}$

Hay varios aspectos generales de esta parte de la decisión que vale la pena resaltar. De un lado, la Corte asumió una vez más la posición de que, cuando se trata de daño inmaterial, las declaraciones judiciales incluidas en el texto de la decisión misma constituyen una 'satisfacción adecuada'. La Corte sostuvo:

La declaración por la Corte de que Nicaragua violó la soberanía territorial de Costa Rica al excavar tres caños y establecer una presencia militar en el territorio en disputa proporciona una satisfacción adecuada por el perjuicio inmaterial sufrido por cuenta de esto. Lo mismo se

\footnotetext{
69 Judgment, par. 49.

70 Ibid.

71 La Corte encontró también que Nicaragua había ocasionado daño inmaterial a Costa Rica, pero que en este caso la declaración judicial respectiva constituía una reparación suficiente, en calidad de satisfacción (Judgment, par. 139).

72 Judgment, pars. 224-227.
} 
aplica a la declaración sobre la violación de las obligaciones a la luz de la providencia de la Corte del 8 de marzo de 2011 sobre medidas provisionales. Finalmente, la declaración de incumplimiento de los derechos de navegación de Costa Rica en las condiciones estipuladas en la sección D suministra una adecuada satisfacción por esa violación. ${ }^{73}$

Un segundo aspecto por destacar es que, una vez más, la Corte declinó ordenar una garantía de no repetición, que es una medida de reparación que se le ha solicitado en forma insistente en casos recientes. La Corte ha asumido que, en ciertas circunstancias, esta medida puede ordenarse, pero nunca hasta ahora ha encontrado que dichas circunstancias se presenten. ${ }^{74}$ En el caso Costa Rica c. Nicaragua, la Corte citó el precedente del caso anterior relativo a los derechos de navegación en el río San Juan y respondió como sigue la solicitud de ordenarle a Nicaragua suministrar unas garantías de no repetición apropiadas:

La solicitud de 'garantías y seguridades apropiadas de no repetición' se basaba inicialmente en la pretendida 'mala fe' de Nicaragua al drenar el caño en 2010 y, ulteriormente, en el incumplimiento por Nicaragua de sus obligaciones a la luz de la providencia de 2011. [... C Como la Corte registró en el caso Derechos de navegación y otros derechos, "no hay ninguna razón para suponer que un Estado cuya conducta o acciones han sido declarados ilegales por la Corte repetirá dicha conducta o acciones en el futuro, ya que su buena fe debe presumirse" y por lo tanto habrá lugar a ordenar seguridades y garantías de no repetición únicamente 'en circunstancias especiales' [...]. Si bien Nicaragua incumplió con las obligaciones emanadas de la providencia de 2011, es necesario tomar en cuenta también el hecho de que Nicaragua cumplió posteriormente con los requerimientos, consagrados en la providencia del 22 de noviembre de 2013, de "abstenerse de cualquier dragado y otras

\footnotetext{
73 Judgment, par. 139. El juez Robinson declaró en su opinión separada que, además, esta situación demandaba que Nicaragua ofreciera excusas a Costa Rica como forma de satisfacción (ibid., Separate opinion of judge Robinson, par. 68).

74 Quintana, Litigation..., p. 1155. Ver también Tams, C. J., "Consular Assistance: Rights, remedies and responsibility: Comments on the ICJ Judgment in the LaGrand Case", European Journal of International Law, 2002, 13, p. 1259; Higgins, Rosalynn, "Remedies in the International Court of Justice", in Higgins, R., Themes and Theories - Selected Essays, Speeches and Writings in International Law, 2009, p. 1354.
} 
actividades en el territorio disputado" y de "ocasionar la evacuación del territorio disputado de cualquier personal, ya sea civil, de policía o de seguridad" [...]. Es de esperarse que Nicaragua adoptará la misma actitud en relación con la situación jurídica resultante de la presente sentencia, en particular en vista del hecho de que la cuestión de la soberanía territorial sobre el territorio disputado ha sido ya resuelta. ${ }^{75}$

Finalmente, un desarrollo de gran interés con relación a la compensación es que por segunda vez en una decisión sobre el fondo la Corte fijó un plazo para que se active el procedimiento derivado relativo a la fijación de la forma y monto de la compensación. La práctica usual en esta materia, seguida desde el caso Canal de Corfú (1949), consiste en que, cuando la Corte encuentra que una parte debe pagar compensación monetaria por daños, decide que las partes deben negociar sobre la forma y monto de la compensación y, en el evento de que dicho acuerdo no sea posible, la propia Corte se reserva la jurisdicción necesaria para determinar esas cuestiones, luego de un procedimiento adicional dedicado por entero a esa cuestión. ${ }^{76}$ En un caso reciente de protección diplomática, la Corte dio un paso novedoso al establecer un plazo fijo para que las partes arribaran a dicho acuerdo y, teniendo en cuenta que se trataba de una afectación de derechos humanos fundamentales y que el procedimiento judicial había durado ya más de una década, decidió que 'la adecuada administración de justicia' exigía que esto sucediera en seis meses, con la precisión de que, si no se lograba acuerdo, se activaría en forma automática un procedimiento derivado sobre compensación, consistente exclusivamente en una fase escrita. ${ }^{77}$

En el caso Costa Rica c. Nicaragua, la Corte repitió el mismo modelo, aunque sin referirse al objeto-materia del litigio y sin invocar el concepto abstracto de 'la adecuada administración de justicia'. La Corte halló que, además del monto preciso de la compensación debida por Nicaragua, las partes deben identificar también 'el daño material pertinente' causado y que, si no logran llegar a un acuerdo en un plazo de doce meses, ella

\footnotetext{
75 Judgment, pars. 139-140.

76 Quintana, Litigation..., pp. 1175-1178.

77 ICJ, Ahmadou Sadio Diallo (Republic of Guinea c. Democratic Republic of the Congo), Merits, Judgment, ICJ Reports 2010, pp. 691-692, par. 164.
} 
misma hará esa determinación luego de un procedimiento interlocutorio. ${ }^{78}$ La fórmula utilizada en la sentencia parece indicar también que, al igual que en el caso Diallo, este procedimiento consistirá exclusivamente en un intercambio de piezas escritas.

Este es un desarrollo positivo, que vale la pena aplaudir, puesto que parece indicar que en relación con la compensación por daños la Corte está asumiendo un papel cada vez más decisorio. En particular, todo señala que la Corte está ahora dispuesta a tomar medidas para evitar que se repitan situaciones pasadas, en las cuales la prolongada demora en organizar la incidencia procesal sobre compensación pudo haber resultado en un detrimento de los derechos de la parte favorecida por la sentencia.

\subsection{Manejo de la evidencia (interrogatorio de peritos)}

$\mathrm{Al}$ igual que en varias instancias recientes ante la CIJ, en estos dos casos hubo lugar a la presentación de evidencia de carácter no documental, en concreto deposiciones de peritos o expertos llamados por las partes. Lo interesante es que, al momento de diseñar la metodología para el examen de los peritos, la Corte consolidó una práctica de reciente extracción que va dirigida a simplificar y abreviar considerablemente el tiempo que toma el interrogatorio de los peritos.

La verdad es que la CIJ no tiene mucha experiencia en la interrogación de peritos o expertos, lo cual se relaciona con el hecho de que los casos en los que la comprobación de los hechos es fundamental siguen siendo una minoría dentro del conjunto de asuntos de los que se ocupa este tribunal. ${ }^{79}$ En los primeros casos en los que esto se presentó, la Corte siguió el modelo utilizado en el sistema jurídico anglosajón, según el cual la interrogación debe agotar, en general, las siguientes etapas:

\footnotetext{
78 Judgment, par. 142. Ver también el dispositif, ibid., p. 229, par. 5 (b) —adoptado por unanimidad-.

79 Ver, en general, Quintana, Litigation..., pp. 439-447; Riddell A. \& Plant, B., Evidence before the International Court of Justice, British Institute of International and Comparative Law, 2009, pp. 307-358; White, G., 'The Use of Experts by the International Court of Justice', in Lowe, c. \& Fitzmaurice, M. (Eds.), Fifty Years of the International Court of Justice - Essays in Honour of Sir Robert Jennings, Cambridge, 1996, p. 528; Foster, C., "New Clothes for the Emperor? Consultation of Experts by the International Court of Justice", Journal of International Dispute Settlement, 2014, 5, p. 139; Peat, D., "The Use of Court-Appointed Experts by the International Court of Justice”, British Year Book of International Law, 2014, 84, p. 271.
} 
i) interrogatorio principal (examination-in-chief), adelantado por la parte que cita al testigo o experto;

ii) contrainterrogatorio (cross-examination), adelantado por la contraparte;

iii) reinterrogatorio (re-direct o re-examination), adelantado nuevamente por la parte que cita al testigo o experto; $; 0$

iv) preguntas por la Corte o por jueces individuales. ${ }^{81}$

En varios casos recientes, la Corte venía dando señales de que, con miras a ahorrar al máximo el escaso tiempo del cual se dispone durante las audiencias públicas, sería preferible omitir del todo el primer paso (interrogatorio principal) y concentrar la sección pertinente de la audiencia en el contrainterrogatorio y reinterrogatorio. Para ello, se le solicita a las partes que, antes de la audiencia, suministren por escrito el texto del testimonio o deposición que tenía planeado presentar el testigo o experto, texto que haría las veces de interrogatorio principal. La Corte ensayó en forma tentativa esta novedosa técnica en por lo menos dos casos recientes y parece haber decidido que este es el nuevo modelo que empleará de aquí en adelante. ${ }^{82}$ En los casos bajo estudio, este importante desarrollo procesal quedó registrado en los siguientes términos:

80 Según la práctica usual, el reinterrogatorio tiene la peculiaridad de que solamente puede versar sobre aquellos temas o cuestiones que hayan surgido durante el contrainterrogatorio.

81 Quintana, Litigation..., p. 441; Mani, c. C., International Adjudication - Procedural Aspects, 1980, pp. 231-232; Lachs, Manfred, "Evidence in the Procedure of the International Court of Justice: Role of the Court", in Bello, E. G. \& Ajibola, B. A. (Eds.), Essays in Honour of Judge Taslim Olawale Elias, 1992, vol. 1, pp. 272-273; Guyomar, Genevieve, Commentaire du Reglement de la Cour international de justice, adoptee le 10 Avril 1978 - Interpretation et pratique, 1983, pp. 421-424; Rosenne, Shabtai, The Law and Practice of the International Court of Justice 1920-1996, 2000, vol. 3, pp. 1346-1360; Tams, Christian, "Article 51", in Oxford Commentary, pp. 1306-1309.

82 ICJ, Whaling in the Antarctic (Australia c. Japan: New Zealand intervening), Judgment, ICJ Reports 2014, pp. 236-237, pars. 16-20; ICJ, Application of the Convention on the Prevention and Punishment of the Crime of Genocide (Croatia c. Serbia), Judgment of 3 February 2015, pars. 20 y ss. La misma metodología se iba a utilizar en el caso Aerial Spraying with herbicide (Ecuador c. Colombia), pero el procedimiento en este caso fue descontinuado por el demandante poco antes de la apertura de las audiencias. El manejo de los peritos y expertos en el primero de estos casos ha dado lugar a una abundante literatura. Ver al respecto: Hamamoto, S, "Procedural Questions in the Whaling Judgment: Admissibility, Intervention and Use of Experts", in Japanese Society of International Law, ICJ Judgment on Whaling in the Antarctic: Its Significance and Implications, 2014; Gros, Guillaume, "The ICJ's Handling of Science in 
Mediante cartas del Secretario fechadas el 4 de febrero 2015, las partes fueron informadas de que ellas debían indicarle a la Corte, a más tardar el 2 de marzo de 2015, los nombres de los peritos que ellas tenían la intención de llamar y comunicar la otra información exigida por el artículo 57 del Reglamento de la Corte. Se informó también a las partes que debían suministrarle a la Corte, a más tardar el 16 de marzo de 2015, declaraciones escritas de dichos peritos (limitadas a un resumen del propio informe de cada perito o a observaciones sobre informes de otros expertos que ya figuren en el expediente del caso) y se les comunicó que estas declaraciones reemplazarían el interrogatorio principal. ${ }^{83}$

Queda claro, entonces, que, salvo que la Corte decida modificar su práctica en esta materia en un futuro (algo que ella siempre es libre de hacer), los peritos y testigos que sean llamados por las partes en un caso ya no serán sujetos a un interrogatorio principal por la parte que los llame y su participación en las audiencias se limitará a responder el contrainterrogatorio de la otra parte, el reinterrogatorio de la parte que lo convocó y las eventuales preguntas de los jueces. En la misma decisión, la Corte describió la mecánica de presentación de este tipo de evidencia:

Después de haber hecho la declaración solemne exigida a la luz del artículo 63 del Reglamento, la parte que llama al perito le solicitará que confirme su declaración escrita. La otra parte tendrá entonces una oportunidad para contra-interrogar sobre el contenido de la declaración escrita del perito o sus informes previos. El re-interrogatorio ulterior se limitará a cuestiones planteadas durante el contra-interrogatorio. Finalmente, los jueces tendrán la oportunidad de formular preguntas al perito. ${ }^{84}$

the Whaling in the Antarctic Case: A Whale of a Case?", Journal of International Dispute Settlement, 2015, 6, pp. 578-620; Mbengue, Makane Moïse, "Between law and science: A commentary on the Whaling in the Antarctic case", Questions of International Law, 2015, 14, pp. 3-12; Scovazzi, Tullio, "Between law and science: Some considerations inspired by the Whaling in the Antarctic judgment", ibid, pp. 13-30; Lima, Lucas Carlos, "Weighing the evidential value of expert opinion: The Whaling Case", ibid, pp. 31-38.

83 Judgment, par. 34. Cursiva añadida. La parte en cursiva de este pasaje figuró en la decisión de la Corte en el caso Convención contra el Genocidio (Croacia) (Judgment of 3 February 2015, par. 20), pero con la importante diferencia de que en ese caso esto se produjo como resultado de un acuerdo de las partes, no de una decisión de la Corte, como en el caso en comento.

84 Ibid. 
Hay varios aspectos de esta nueva práctica que ameritan una reflexión adicional. En primer lugar, cabe preguntarse si efectivamente el procedimiento del interrogatorio principal puede ser sustituido por el envío a la Corte de una declaración escrita firmada por el perito y la ulterior 'confirmación' de dicha declaración por la persona en cuestión. Cabe recordar aquí que en la práctica de la CIJ el principal efecto que tiene la participación de peritos y testigos en las audiencias es de carácter puramente psicológico, de la misma manera como la justificación última para la organización de todo el procedimiento oral se refiere al impacto, consciente o subconsciente, que las actuaciones de las partes litigantes en las audiencias públicas tiene sobre la Corte y sobre sus miembros, así como sobre la contraparte. ${ }^{85}$ Eliminar del todo el interrogatorio en vivo de un perito por los abogados de la parte que lo convocó significa que ese Estado pierde del todo el efecto que buscaba lograr con la deposición del perito y es por lo menos cuestionable que un efecto similar se logre simplemente con el expediente de suministrarle a la Corte el récord escrito de lo que hubiera dicho el perito si se le hubiera sometido a ese interrogatorio.

En segundo lugar, parecería que el sistema de eliminar el interrogatorio principal se aplicará únicamente a aquellos peritos (y testigos) que, como suele suceder, ya han presentado ante la Corte una deposición o un testimonio como parte del procedimiento escrito. En los pasajes transcritos, la Corte señaló expresamente que las declaraciones escritas para ser enviadas a la Corte antes de las audiencias (y que reemplazarán al interrogatorio principal) debían limitarse a "un resumen del propio informe de cada perito o a observaciones sobre informes de otros expertos que ya figuren en el expediente del caso" y que el contrainterrogatorio de la otra parte debe versar sobre "el contenido de la declaración escrita del perito o sus informes previos". Queda, por lo tanto, la impresión de que los peritos a los que se aplicaría el nuevo sistema son aquellos cuyas deposiciones sustantivas ya forman parte del expediente del caso, por haber sido sometidas como un anexo de los alegatos escritos.

Pero cabe preguntarse ¿qué sucede con un perito nuevo, es decir, uno que una parte identifique después de haber entregado sus alegatos escritos y quiera llamar a declarar y para tal efecto incluya sus datos en la comunicación a la Corte prevista en el artículo 57 del Reglamento? ¿Vale la pena en este caso que el primer acercamiento de la Corte — y de la contraparte- con el contenido de su declaración sea mediante un escrito (ya

85 Quintana, Litigation..., p. 348. 
no un resumen) que se presente poco antes de las audiencias, o se justifica en este caso mantener el viejo sistema y sujetar a esta persona a un interrogatorio principal por la parte que lo llama?

Finalmente, la práctica usada en el caso de la Convención contra el genocidio (Croacia c. Serbia) revela que también es posible que la contraparte no desee contrainterrogar a un perito presentado por una parte y lo comunique así oportunamente a la Corte. ${ }^{86} \mathrm{Y}$ como si no hay contrainterrogatorio tampoco hay lugar a reinterrogatorio, en este caso no se justificaría hacer viajar al perito a La Haya y presentarlo ante la Corte, a menos que la propia Corte o los jueces tengan de antemano la intención de formularle preguntas, algo que en muchos casos surgirá del intercambio generado por la secuencia tradicional de un interrogatorio principal seguido de un contrainterrogatorio y de un reinterrogatorio. Bajo el sistema previo, incluso en casos en los que no había contrainterrogatorio, la presencia del perito en la sala era útil por sí misma, ya que del mero interrogatorio principal podía surgir la necesidad de una pregunta por la Corte o por un juez, pero al eliminarse esa etapa el elemento que pasa a adquirir prominencia es el contrainterrogatorio, lo cual le da una herramienta poderosa a la contraparte para maniobrar con el fin de que determinado perito no participe en la audiencia. Es cierto que el contenido de la declaración escrita formulada por ese perito quedará en todo caso en el expediente y podrá ser tomada en consideración por la Corte como evidencia, pero no debe olvidarse lo dicho arriba sobre el efecto psicológico que tiene la presentación de este tipo de evidencia en un tribunal internacional como la CIJ.

Estos son aspectos del nuevo sistema que no quedan del todo claros y habrá que esperar a que en casos futuros la Corte incluya en sus decisiones aclaraciones sobre la forma como se va a aplicar en circunstancias como las descritas. Quizá sería conveniente que la Corte considere adoptar una directriz práctica sobre este aspecto del procedimiento, en la cual se aclaren cuáles son las reglas del juego a las que los Estados litigantes deben someterse si escogen recurrir a este medio de prueba. Sin embargo, dada la reticencia tradicional de la Corte a introducir cambios a sus instrumentos reguladores, es más realista aguardar a que la cuestión surja nuevamente en casos futuros y registrar la forma como la Corte decide manejarla. ${ }^{87}$

\footnotetext{
86 ICJ, Application of the Convention on the Prevention and Punishment of the Crime of Genocide (Croatia c. Serbia), Judgment of 3 February 2015, pars. 25 y ss.

87 También sobre el tema de los medios de prueba la Corte reiteró su jurisprudencia
} 


\subsection{Costas judiciales}

El tema del pago de costas judiciales en el régimen de la CIJ es relativamente simple: aunque tanto el Estatuto (artículo 64) como el Reglamento (artículo 97) prevén que la Corte puede otorgar costas cuando lo considere conveniente, nunca hasta ahora — desde la época de la CPJI- el tribunal ha hecho uso de esa facultad. ${ }^{88}$

En sus conclusiones finales en Costa Rica c. Nicaragua, el demandante solicitó formalmente a la Corte ordenarle a Nicaragua que pagara todas las costas y gastos incurridos por Costa Rica al solicitar y obtener la providencia sobre medidas provisionales del 22 de noviembre de $2013 .{ }^{89}$

Como se observa, la solicitud de Costa Rica tenía un alcance relativamente modesto, puesto que no se refería a la totalidad de las costas del proceso, sino únicamente a aquellas generadas por la incidencia procesal generada a raíz de su segunda solicitud de medidas provisionales. Debe recordarse que desde el 8 de marzo de 2011 la Corte había proferido una providencia indicando ciertas medidas provisionales que debían cumplirse por ambas partes en el caso. ${ }^{90}$ En mayo de 2013, enfrentada a ciertas acciones de Nicaragua en el área en disputa, Costa Rica solicitó a la Corte modificar tales medidas y Nicaragua, al responder a esta solicitud, pidió también ciertas modificaciones a su providencia de 2011. La Corte negó ambas solicitudes, pero reafirmó las medidas que ya había indicado. ${ }^{91}$ Acto seguido, en septiembre de 2013, Costa Rica, nuevamente impelida por actuaciones de Nicaragua en la zona en disputa, formuló una segunda solicitud, pidiendo esta vez la indicación de nuevas medidas provisionales de protección, la cual fue respondida favorablemente por la Corte mediante providencia del 22 de noviembre de ese año. ${ }^{92}$ En la misma decisión, la Corte reafirmó por segunda vez las medidas que había indicado en marzo de 2011.

respecto del limitado valor que se le debe asignar a las declaraciones escritas (affidavits) de particulares preparadas especialmente para el caso (Judgment, par. 83), así como a los mapas (ibid., par. 85).

88 Sobre el tema de las costas en la práctica de la Corte, ver Quintana, Litigation..., pp. 543-545; Oxford Commentary, pp. 1598-1604; Kolb, The ICJ, pp. 1002-1006.

89 Judgment, par. 49.

90 Order of $8 / 3 / 2011$, p. 6 .

91 Order of $16 / 7 / 2013$, p. 230.

92 Order of $22 / 11 / 2013$, p. 354. 
En retrospectiva, queda claro que, si Nicaragua hubiera dado cumplimiento a la providencia de marzo de 2011, Costa Rica se habría ahorrado el trámite de buscar ante la Corte la modificación de la providencia inicial y el trámite aún más dispendioso de solicitar nuevas medidas de protección. Por lo tanto, la solicitud de pago de costas de Costa Rica, confinada como estaba desde un comienzo al (segundo) proceso incidental sobre medidas provisionales, resultaba enteramente razonable.

La mayoría de la Corte, sin embargo, prefirió atenerse a la actitud inveteradamente conservadora que ha adoptado siempre en materia de costas y rechazó la solicitud de Costa Rica. Aunque la Corte concluyó que Nicaragua efectivamente había incumplido su providencia sobre medidas provisionales del 8 de marzo de 2011 y que esta violación había hecho necesario que Costa Rica iniciara un segundo procedimiento sobre medidas provisionales, se contentó con declarar que en las circunstancias del caso una condena en costas "no sería apropiada". ${ }^{33}$

Lo interesante es que hubo varios jueces que se apartaron de esta postura y llegaron al extremo de votar en contra del párrafo del dispositifen el cual la Corte rechazó la solicitud de Costa Rica sobre pago de costas. ${ }^{94}$ Tres respetados miembros de la Corte — los jueces Tomka, Greenwood y Sebutinde- y el juez ad hoc designado por Costa Rica, Dugard, votaron en contra de este pasaje de la decisión y añadieron a la sentencia una declaración conjunta en la cual lamentaron que la mayoría de los jueces hubieran declinado penalizar a Nicaragua por haber forzado a Costa Rica a litigar por segunda vez en materia de medidas provisionales y se hubieran limitado a emitir el pronunciamiento 'délfico' de que ese no era el curso de acción 'apropiado' en las circunstancias del caso. ${ }^{95}$ Luego de recapitular los hechos del caso, los cuales mostraban con claridad que la responsabilidad de haber dado lugar al segundo pleito sobre medidas provisionales era enteramente de Nicaragua, estos jueces expresaron lo siguiente:

\footnotetext{
93 Judgment, par. 144. Ver también ibid., par. 129.

94 Esta sección de la parte operativa de la sentencia consiste en el párrafo (5), que fue dividido en tres subsecciones, las dos primeras adoptadas por unanimidad y la última por 12 votos contra 4. El hecho mismo de que esa parte del dispositif tuviera que ser fragmentada refleja que los cuatro jueces que votaron en contra de este aspecto fueron muy firmes en su posición de que en este caso se justificaba el otorgamiento de costas, siquiera parciales, al demandante, y mantuvieron esa postura hasta el último momento.

95 Judgment, Joint declaration of judges Tomka, Greenwood, Sebutinde and judge ad hoc Dugard, par. 9.
} 
Resulta ilógico que la Corte adopte una postura bajo la cual una parte que ha sido víctima de una violación de medidas provisionales indicadas por la Corte sea tratada en forma menos favorable si incurre en gastos al retornar a la Corte para buscar una reparación, que si tomara medidas unilaterales para corregir el daño ocasionado por esa violación. [...] Consideramos que [las del presente caso] son circunstancias excepcionales que justificaban que la Corte ejerciera la facultad que lo otorga el artículo 64 del Estatuto. Es verdad que la Corte nunca hasta ahora ha ejercido esa facultad pero raramente se le ha pedido que lo haga y ninguno de los casos en los que se ha pedido el pago de costas ha sido ni remotamente comparable con el presente caso. La facultad de indicar medidas provisionales es de la mayor importancia para el mantenimiento de la integridad de los procesos ante la Corte. Las medidas que se indican son jurídicamente vinculantes y su violación constituye una violación autónoma de obligaciones jurídicas, totalmente diferente del fondo del caso. La Corte y los Estados que comparecen ante ella están legitimados para asumir que un Estado que litiga de buena fe será escrupuloso en darle cumplimiento a dichas medidas. Si por el hecho de que no lo haga se genera la necesidad de una audiencia adicional, es apenas justo que dicho Estado asuma los costos involucrados. ${ }^{96}$

Queda por verse si en futuros casos en los que un Estado parte en un caso que se vea perjudicado por las acciones de otro Estado y las consecuencias procesales que esto pueda tener intentará nuevamente recuperar parte del dinero que invierta en el manejo del litigio y, sobre todo, si la mayoría de la Corte se mostrará más sensible frente a eso.

\section{Observaciones finales}

Los dos litigios entre Costa Rica y Nicaragua fallados en diciembre de 2015 le suministraron a la CIJ una buena oportunidad para refinar su doctrina sobre ciertas cuestiones relativas al procedimiento que se sigue ante ella.

Haciendo abstracción de las cuestiones de fondo en juego en ambos casos, el examen precedente permite concluir que la Corte desarrolló en varios sentidos su doctrina sobre aspectos de su procedimiento en los

96 Ibid., pars. 7-8. 
que había escasa práctica, como puede ser la modificación de medidas provisionales, la supervisión del cumplimiento de medidas ya indicadas, la compensación como mecanismo de reparación por violaciones de obligaciones internacionales o la metodología para el interrogatorio de peritos. En materias como la admisibilidad de demandas reconvencionales, las garantías de no repetición o el pago de costas, la mayoría de la Corte adoptó una actitud más conservadora, reafirmando posiciones adoptadas por ella en el pasado y sin introducir mayores modificaciones en la práctica.

En cuanto a la figura poco empleada de la acumulación de procedimientos, finalmente, hay razones que permiten concluir que en las circunstancias de estos casos no se justificaba tomar esa medida, la cual fue percibida como un poco artificial y tuvo escasas consecuencias prácticas. Si bien es cierto que la opinión de las partes es solo un factor por tener en cuenta y no puede afectar la amplia discreción que la Corte posee en la materia, en casos en los que un Estado plantea objeciones fundadas respecto de la conveniencia de acumular varios procedimientos la Corte debería actuar con extrema circunspección a este respecto. ${ }^{97} \mathrm{El}$ resultado de los dos casos justifica la conclusión de que en este caso quizá se justificaba darle más peso a la argumentación aducida por Costa Rica para impugnar la pertinencia de la acumulación, buena parte de la cual resultó vindicada al conocerse la decisión final de la Corte. ${ }^{98}$

\section{Referencias}

\section{Doctrina}

Aceves, W. J., "LaGrand (Germany c. United States), Judgment", American Journal of International Law, 2002, 96, pp. 210-218.

Antonopoulos, C., Counterclaims before the International Court of Justice, Springer-TMC Asser Institute, The Hague, 2011.

Bekker, P. H. F., "Provisional Measures in the Recent Practice of the International Court of Justice", International Law FORUM du droit international, 2005, 7, pp. 24-32.

\footnotetext{
97 Para un ejemplo, ver ICJ, Fisheries jurisdiction (Federal Republic of Germany c. Iceland), Merits, Judgment, ICJ Reports 1974, p. 177, par. 8.
}

98 Orders of $17 / 4 / 2013$, pp. $169-170$, par. 17; p. 186, par. 9. 
Brown, C., A Common Law of International Adjudication, Oxford University Press, Oxford, 2009.

Foster, C., "New Clothes for the Emperor? Consultation of Experts by the International Court of Justice", Journal of International Dispute Settlement, 2014, 5, p. 139.

Frowein, J. A., "Provisional Measures by the International Court of Justice: The LaGrand Case", Zeitschrift für ausländisches öffentliches Recht und Völkerrecht, 2002, 62, pp. 55-60.

Gattini, A., "Breach of the obligation to prevent and reparation thereof in the ICJ's genocide judgment", European Journal of International Law, 2007, 18-4, pp. 695-713.

Guyomar, G., Commentaire du Reglement de la Courinternational de justice, adoptee le 10 Avril 1978 - Interpretation et pratique, Pedone, Paris, 1983.

Higgins, R., "Remedies in the International Court of Justice", en Higgins, R., Themes and theories - Selected essays, speeches, and writings in international law, Oxford University Press, Oxford, 2009, pp. 1352-1358.

Jennings, S. R., "The LaGrand Case", The Law and Practice of International Courts and Tribunals, 2002, 1, pp. 13-54.

Kolb, R., "Note on New International Case-law Concerning the Binding Character of Provisional Measures", Nordic Journal of International Law, 2005, 74, pp. 117-130.

Kolb, R., The International Court of Justice, Hart Publishing, 2013.

Lachs, M., "Evidence in the Procedure of the International Court of Justice: Role of the Court", in Bello, E. G. \& Ajibola, B. A. (Eds.), Essays in Honour of Judge Taslim Olawale Elias, 1992.

Mani, c. C., International Adjudication - Procedural Aspects, New Delhi, 1980.

Matringe, J., "L'arret de la Cour internationale de Justice dans l'affaire LaGrand (Allemagne c. Etats-Unis d'Amérique) du 27 juin 2001", Annuaire Francais du Droit International, 2001, 48, pp. 215-256.

Mendelson, M., "State responsibility for breach of interim protection orders of the International Court of Justice", en Fitzmaurice, M. \& Sarooshi, D. (Eds.), Issues of State responsibility before international judicial institutions, London, 2004, pp. 35-53.

Mennecke M. \& Ch. Tams, “'The LaGrand case (Germany c. United States of America)", International and Comparative Law Quarterly, vol. 51 (2002), pp. 449-455.

Murphy, S., "Counter-claims", en Zimmermann, A. et al. (Eds.), The Statute of the International Court of Justice - A commentary, $2^{\text {nd }}$ ed., Oxford University Press, Oxford, 2012, pp. 1000-1025. 
Nouvel, Y., "La recevabilite des demandes reconventionnelles devant la Cour internationale de Justice a la lumiere de deux ordonnances recentes", Annuaire Français du droit international, 1998, 44, pp. 324-336.

Orakhelashvili, A., "Questions of International Judicial Jurisdiction in the LaGrand Case", Leiden Journal of International Law, 2002, 15, pp. 105-130.

Peat, D., "The Use of Court-Appointed Experts by the International Court of Justice", British Year Book of International Law, 2014.

Quintana, J. J., Litigation at the International Court of Justice, practice and procedure, Brill-Nijhoff, Leiden-Boston, 2015.

Riddell A. \& Plant, B., Evidence before the International Court of Justice, British Institute of International and Comparative Law, 2009.

Rigaux, F., «Les demandes reconventionelles devant la Cour internationale de Justice», in Ando, N., McWhinney, E. \& Wolfrum, R. (Eds.), Liber amicorum judge Shigeru Oda, 2002, vol. 2, pp. 935-945.

Rosenne, S., The Law and Practice of the International Court of Justice 19201996, Martinus Nijhoff, 2000.

Rosenne, S., Provisional measures in international law, Oxford University Press, Oxford, 2005.

Rosenne, S., "Counter-claims in the International Court of Justice revisited", in Rosenne, S., Essays on international law and practice, 2007, pp. 267-293.

Salerno, F., "La demande reconventionnelle dans la procedure de la Cour Internationale de Justice", Revue General du Droit International Publique, 1999, 103, pp. 371-374.

Sarmiento Lamus, A., "Revocation and modification of provisional measures orders in the International Court of Justice: the Court's order regarding certain activities carried out by Nicaragua in the border area and the case concerning construction of a road in Costa Rica along the San Juan river joint proceedings", The Law and Practice of International Courts and Tribunals, 2013, 12 (3).

Tams, C., "Consular assistance: rights, remedies and responsibility: comments on the ICJ judgment in the LaGrand case", European Journal of International Law, 2002, 13, pp. 1257-1259.

Tams, C., "Article 51", en Zimmermann, A. et al. (Eds.), The Statute of the International Court of Justice - A commentary, $2^{\text {nd }}$ ed., Oxford University Press, Oxford, 2012, pp. 1306-1309. 
Tams, C. J., "Consular Assistance: Rights, remedies and responsibility: Comments on the ICJ Judgment in the LaGrand Case", European Journal of International Law, 2002, 13.

Tzanakapoulos, A., "Provisional Measures Indicated by International Courts: Emergence of a General Principle of International Law", Revue Hellenique de Droit International, 2004, 57, pp. 53-84.

White, G., 'The Use of Experts by the International Court of Justice', in Lowe, c. \& Fitzmaurice, M. (Eds.), Fifty Years of the International Court of Justice - Essays in Honour of Sir Robert Jennings, Cambridge, 1996.

Wittich, Stefan, "Non-material damage and monetary reparation in international law", Finnish Yearbook of International Law, 2004, 15, pp. 321-368.

Yang, X., "Thou Shalt Not Violate Provisional Measures", Cambridge Law Journal, 2001, 60, pp. 441-446.

Yee, S., "Article 40", in Zimmermann, A. et al. (Eds.), The Statute of the International Court of Justice - A commentary, Oxford University Press, Oxford, 2012, pp. 975-982.

\section{Jurisprudencia citada}

ICJ, Ahmadou Sadio Diallo (Republic of Guinea c. Democratic Republic of the Congo), Merits, Judgment, ICJ Reports 2010, pp. 691-692, par. 164.

ICJ, Application of the Convention on the Prevention and Punishment of the Crime of Genocide (Bosnia and Herzegovina c. Yugoslavia), Counter-claims, order of 17 December 1997, ICJ Reports 1997, p. 256, par. 27.

ICJ, Application of the Convention on the Prevention and Punishment of the Crime of Genocide (Bosnia and Herzegovina c. Serbia and Montenegro), Judgment of 26 February 2007, pars. 458, 467-469.

ICJ, Application of the Convention on the Prevention and Punishment of the Crime of Genocide (Croatia c. Serbia), Judgment of 3 February 2015, pars. 20 y ss.

ICJ, Application of the Convention on the Prevention and Punishment of the Crime of Genocide (Croatia c. Serbia), Judgment of 3 February 2015 , pars. 25 y ss.

ICJ, Armed activities on the territory of the Congo (Democratic Republic of the Congo c. Uganda), Judgment, ICJ Reports 2005, p. 258, par. 263. 
ICJ, Armed activities on the territory of the Congo (Democratic Republic of the Congo c. Uganda), Judgment, ICJ Reports 2005, p. 282, par. $345(7)$.

ICJ, Armed activities on the territory of the Congo (Democratic Republic of the Congo c. Uganda), Order of 1 July 2015, Declaration of judge Cançado Trindade.

ICJ, Avena and other Mexican nationals (Mexico c. United States of America), Judgment, ICJ Reports 2004, p. 70, par. 152.

ICJ, Certain activities carried out by Nicaragua in the border area (Costa Rica c. Nicaragua), Provisional measures, Order of 8 March 2011, ICJ Reports 2011, p. 6.

ICJ, Certain activities carried out by Nicaragua in the border area (Costa Rica c. Nicaragua), Joinder of proceedings, Order of 17 April 2013, ICJ Reports 2013, p. 166; Construction of a road in Costa Rica along the San Juan river (Nicaragua c. Costa Rica), Joinder of proceedings, Order of 17 April 2013, ICJ Reports 2013, p. 184.

ICJ, Certain activities carried out by Nicaragua in the border area (Costa Rica c. Nicaragua); Construction of a road in Costa Rica along the San Juan river (Nicaragua c. Costa Rica), Counter-claims, Order of 18 April 2013, ICJ Reports 2013, p. 200.

ICJ, Certain activities carried out by Nicaragua in the border area (Costa Rica c. Nicaragua); Construction of a road in Costa Rica along the San Juan river (Nicaragua c. Costa Rica), Order of 16 July 2013, Provisional measures, ICJ Reports 2013, p. 230.

ICJ, Certain activities carried out by Nicaragua in the border area (Costa Rica c. Nicaragua); Construction of a road in Costa Rica along the San Juan river (Nicaragua c. Costa Rica), Provisional measures, Order of 22 November 2013, ICJ Reports 2013, p. 354.

ICJ, Certain activities carried out by Nicaragua in the border area (Costa Rica c. Nicaragua); Construction of a road in Costa Rica along the San Juan river (Nicaragua c. Costa Rica), Merits, Judgment of 16 December 2015.

ICJ, Construction of a road in Costa Rica along the San Juan river (Nicaragua c. Costa Rica); Certain activities carried out by Nicaragua in the border area (Costa Rica c. Nicaragua), Provisional measures, Order of 13 December 2013, ICJ Reports 2013, p. 398.

ICJ, Fisheries jurisdiction (Federal Republic of Germany c. Iceland), Merits, Judgment, ICJ Reports 1974, p. 177, par. 8. 
ICJ, Jurisdictional immunities, Opinión disidente del juez Cançado Trindade, ICJ Reports 2010, p. 342, par. 30.

ICJ, LaGrand (Germany c. United States of America), Judgment, ICJ Reports 2001, p. 484, para. 45.

ICJ, Land and maritime boundary between Cameroon and Nigeria (Cameroon c. Nigeria: Equatorial Guinea intervening), Judgment, ICJ Reports 2002, p. 453, pars. 321-322.

ICJ, Land and maritime boundary between Cameroon and Nigeria, Merits, Judgment, ICJ Reports 2002, p. 453, par. 321.

ICJ, Questions relating to the seizure of certain documents and data (Timor Leste c. Australia), Request for the modification of the order indicating provisional measures of 3 March 2014, Order of 22 April 2015, par. 12.

ICJ, Request for interpretation of the judgment of 31 March 2004 in the case concerning Avena and other Mexican nationals (Mexico c. United States of America) (Mexico c. United States of America), Judgment of 19 January 2009, pars. 50-53 y par. 61 (2) (dispositif); ibid., 58-60 y par. 61 (4) (dispositif).

ICJ, Whaling in the Antarctic (Australia c. Japan: New Zealand intervening), Judgment, ICJ Reports 2014, pp. 236-237, pars. 16-20. 
